Article

\title{
Evaluation of the Polarimetric-Radar Quantitative Precipitation Estimates of an Extremely Heavy Rainfall Event and Nine Common Rainfall Events in Guangzhou
}

\author{
Yang Zhang ${ }^{1,2}$, Liping Liu ${ }^{1,2, *}$, Hao Wen ${ }^{3}$, Chong $\mathrm{Wu}^{2}$ and Yonghua Zhang ${ }^{4,5}$ \\ 1 Collaborative Innovation Center on Forecast and Evaluation of Meteorological Disasters, Nanjing University \\ of Information Science and Technology, Nanjing 210044, China; zhangyang_cams@163.com \\ 2 State Key Laboratory of Severe Weather, Chinese Academy of Meteorological Sciences, Beijing 100081, China; \\ wuchong89@foxmail.com \\ 3 Meteorological Observation Centre of China Meteorological Administration, Beijing 100081, China; \\ haowenfly@163.com \\ 4 School of Geographical Sciences, Nanjing University of Information Science and Technology, Nanjing 210044, \\ China; zhangyh@grmc.gov.cn \\ 5 Guangdong Meteorological Observation Data Center, Guangzhou 510640, China \\ * Correspondence: liulp@cma.gov.cn
}

Received: 26 April 2018; Accepted: 20 August 2018; Published: 22 August 2018

check for updates

\begin{abstract}
The development and application of operational polarimetric radar (PR) in China is still in its infancy. In this study, an operational PR quantitative precipitation estimation (QPE) algorithm is suggested based on data for PR hydrometeor classification and local drop size distribution (DSD). Even though this algorithm performs well for conventional rainfall events, in which hourly rainfall accumulations are less than $50 \mathrm{~mm}$, the capability of a PR to estimate extremely heavy rainfall remains unclear. The proposed algorithm is used for nine different types of rainfall events that occurred in Guangzhou, China, in 2016 and for an extremely heavy rainfall event that occurred in Guangzhou on 6 May 2017. It performs well for all data of these nine rainfall events and for light-to-moderate rain (hourly accumulation $<50 \mathrm{~mm}$ ) in this extremely heavy rainfall event. However, it severely underestimated heavy rain $(>50 \mathrm{~mm})$ and the extremely heavy rain at stations where total rainfall exceeded $300 \mathrm{~mm}$ within $5 \mathrm{~h}$ in this extremely heavy rainfall event. To analyze the reasons for underestimation, a rain microphysics retrieval algorithm is presented to retrieve $D_{\mathrm{m}}$ and $N_{\mathrm{w}}$ from the PR measurements. The DSD characteristics and the factors affecting QPE are analyzed based on $D_{\mathrm{m}}$ and $N_{\mathrm{w}}$. The results indicate that compared with statistical DSD data in Yangjiang (estimators are derived from these data), the average raindrop diameter during this rainfall event occurred on 6 May 2017 was much smaller and the number concentration was higher. The algorithm underestimated the precipitation with small and midsize particles, but overestimated the precipitation with midsize and large particles. Underestimations occurred when $D_{\mathrm{m}}$ and $N_{\mathrm{w}}$ are both very large, and the severe underestimations for heavy rain are mainly due to these particles. It is verified that some of these particles are associated with melting hail. Owing to the big differences in DSD characteristics, $R\left(K_{\mathrm{DP}}\right.$, $\left.Z_{\mathrm{DR}}\right)$ underestimates most heavy rain. Therefore, $R\left(A_{\mathrm{H}}\right)$, which is least sensitive to DSD variations, replaces $R\left(K_{\mathrm{DP}}, Z_{\mathrm{DR}}\right)$ to estimate precipitation. This improved algorithm performs well even for extremely heavy rain. These results are important for evaluating S-band Doppler radar polarization updates in China.
\end{abstract}

Keywords: quantitative precipitation estimation; drop size distribution; extremely heavy rain; error analysis 


\section{Introduction}

Polarimetric radar (PR) can provide both backscatter and differential propagation phase information; therefore, this type of radar has significant advantages over single polarization radar. One of the advantages of PR is quantitative precipitation estimation (QPE) by using the PR variables. Previous studies have shown that polarimetric precipitation estimation (PPE) techniques are more robust with respect to drop size distribution (DSD) variations and the presence of hail than are the conventional $Z-R$ relationship (here, $R$ is the radar rainfall rate and $Z$ is the radar-reflectivity factor) [1-5]. However, DSD variability and hail contamination can still introduce QPE errors when only a single polarimetric variable is used in the PPE [6]. To avoid large observational errors in $Z_{D R}$ and $K_{\mathrm{DP}}$ at lower signal-to-noise ratios (SNRs) and to reduce the impact of DSD variability on the precipitation estimation, multiple relationships between polarimetric variables and rainfall (e.g., $R\left(Z_{\mathrm{H}}\right)$, $R\left(Z_{\mathrm{H}}, Z_{\mathrm{DR}}\right)$, and $\left.R\left(K_{\mathrm{DP}}\right)\right)$ are often used depending on the type of radar echo. By combining the merits of these different relationships for various rain intensities, Ryzhkov et al. [6] developed a "synthetic" algorithm that uses different combinations of radar variables depending on the rain rate estimates by using the conventional $Z-R$ relationship; their synthetic algorithm was evaluated during the 2002-2003 JPOLE experiment conducted in Oklahoma. Cifelli et al. [7] developed a synthetic algorithm based on the thresholds of $Z_{\mathrm{H}}, Z_{\mathrm{DR}}$, and $K_{\mathrm{DP}}$ and this algorithm was tested on the Colorado State University (CSU)-CHILL radar.

Although relationships between $R$ and polarimetric variables are less prone to DSD variability, they must still be modified according to DSD data in different regions owing to cloud and precipitation microphysical processes that are regionally dependent [6,8-10]. Even in the same region, DSD can vary in terms of precipitation type (e.g., stratus clouds or convective clouds) and rainfall rate. Wu and Liu [11] statistically analyzed the DSD- $R$ relationship in the Tibetan Plateau and in Southern China and found that DSD varies significantly with $R$. Wu et al. [12] and Zhang et al. [13] suggest that Z-R relationships derived from the DSD vary significantly with $R$ even for one rainfall event. Despite many attempts to change the Z-R relationship in real time to improve QPE accuracy, the QPE performance remains unsatisfactory for heavy rain [13-15].

QPE for heavy rainfall is a challenge we may meet. Another challenge is the estimation of rain mixed with hail. Conventional radar rainfall estimates that were obtained from $Z-R$ relationships deteriorate in the presence of mixed-phase and frozen hydrometeors. The $R\left(Z_{\mathrm{H}}, Z_{\mathrm{DR}}\right)$ relationship is less prone to DSD variability but is not immune to hail contamination. Rainfall algorithms based on $K_{\mathrm{DP}}$ are more robust in the presence of hail but are not optimal for light rain in the S-band [16,17]. Wang et al. [18] attempted to use $H_{\mathrm{DR}}$ to determine a hail region and then estimate the liquid precipitation in the associated rain area. However, small mixtures of hail and rainfall are difficult to identify with radar reflectivity alone. Misidentification of rain and precipitation ice often leads to poorly estimated rainfall and has important implications for flood forecasting [7]. The challenges of high-plain meteorological environments have led to the development of an algorithm guided by the precipitation ice fraction in the radar volume. Golestani et al. [19] developed the CSU-ICE optimization algorithm in which $Z_{\mathrm{DR}}$ is used to calculate the ice-fraction index, but unfortunately it performs poorly for $38 \mathrm{dBZ}<Z_{\mathrm{H}}<45 \mathrm{dBZ}$ [7]. Therefore, a new rainfall algorithm was developed using hydrometeor identification (HID) to guide the choice of a particular QPE algorithm [7]. Precipitation is classified as rain, mixture, and ice. Drizzle, moderate rain, and heavy rain are included in the rain category; the mixture category includes wet snow and a rain-hail mixture; and the ice category includes dry snow, graupel, and hail. QPE is conducted in a rain and mixture area.

Despite all the progress in polarimetric rainfall measurements, an algorithm that can resolve all these issues for any scenario does not exist. A synthetic algorithm that uses $Z_{\mathrm{H}}, Z_{\mathrm{DR}}$, and $K_{\mathrm{DP}}$ can theoretically capture the full range of local DSD variability. However, when the DSD characteristics become significantly different from previous characteristics, the QPE performance will be unpredictable. As a possible radar variable for rainfall estimation, specific attenuation (for horizontal polarization) $A_{\mathrm{H}}$ is more directly related to rain rate and liquid water content compared with $Z_{\mathrm{H}}$, and it is immune to 
radar miscalibration, partial beam blockage, and impacts of wet radomes. Compared with algorithms based on $Z_{\mathrm{H}}, Z_{\mathrm{DR}}$, and $K_{\mathrm{DP}}$, rainfall estimations utilizing $A_{\mathrm{H}}$ are less sensitive to DSD variations [20,21]. The use of $R\left(A_{\mathrm{H}}\right)$ was originally $\mathrm{X}$-band and $\mathrm{C}$-band motivated, but it has applied to the S-band as well, which was verified by Ryzhkov [22]. $R\left(A_{\mathrm{H}}\right)$ was first used for X-band radars during the NASA Iowa Flood Studies field campaign, and was found to have excellent performance [23]. A new estimator $R\left(A_{\mathrm{H}}, Z_{\mathrm{DR}}\right)$ was proposed by Keenan [24] for C-band estimation and proposed by Thurai et al. [25] for X-band estimation, respectively. This has also been extended to S-band by Thomposon et al. [26]. Even though these estimators only offer significant skill at S-band for $R\left(A_{\mathrm{H}}\right)$ or at $\mathrm{X}$ band for $R\left(A_{\mathrm{H}}\right.$, $\left.Z_{\mathrm{DR}}\right)$, Thomposon et al. [26] states that the utility of $R\left(A_{\mathrm{H}}\right)$ or $R\left(A_{\mathrm{H}}, Z_{\mathrm{DR}}\right)$ provide the possibility of solving the problems discussed above.

In 2016, the new-generation S-band weather radar in Guangdong Province in China was updated to PR. On 6 May 2017, an extremely heavy rainfall event (here after this rainfall event) was observed in the low-latitude summer. During this heavy rainfall event, rain-gauge observations broke the historical record for 3-h rainfall accumulation in Guangdong and the historical record for single-day rainfall accumulation in Guangzhou City, in Guangdong Province. According to PR observations, hail and graupel melted completely and became liquid water before reaching the ground, thereby altering the DSD structure. Therefore, the QPE algorithm for this rainfall event should differ significantly from those used for previous events. The PPE performance must be examined for this extremely heavy rainfall.

So far, eight S-band PRs have been built in Guangdong Province. By 2020, more than 100 S-band PRs will be built or upgraded in China. The evaluation of PR capability to estimate rain, especially heavy rain, is an important avenue for future research. In this study, an operational QPE algorithm based on a local DSD and mixed-phase precipitation identification is proposed and applied to some rainfall events. This algorithm performs well for most rainfall events investigated in this study. However, rainfall characteristics of this event are so different from the conventional rainfall events occurred in Guangdong, in which hourly rainfall accumulations are less than $50 \mathrm{~mm}$. The main motivation for this study is to analyze the PR capability for estimating severe precipitation, such as this rainfall event and to study the main factors affecting QPE. The performance of PPE and the possible reasons for biases in precipitation estimation (i.e., DSD variations, precipitation phase, and other factors) are analyzed in detail. The method to improve QPE performance on the basis of the reasons for QPE errors is also discussed in this study.

In Section 2, we introduce the measurement instruments and analysis of the rainfall event. In Section 3, we introduce our PPE algorithm, evaluation method, and the rain microphysics retrieval algorithm. In Section 4, we analyze the performance of nine rainfall events and the extremely heavy rainfall event introduced in this study, respectively. In Section 5, we explore possible reasons for biases in the precipitation estimation for this heavy rainstorm. In Section 6, we improve the algorithm and verify its effect. Finally, in Section 7, we present our conclusions.

\section{Measurement Instruments and Rainfall Event}

A heavy rainfall event occurred throughout Guangdong Province on 6 May 2017, and severe rain occurred in Guangzhou City during 1900-2400 UTC. The rainfall observed at many automatic weather stations (AWSs) broke historical records and caused numerous flooding disasters. Figure 1a shows the distribution of total rainfall during 1900-2400 UTC based on AWS observations. During this period, 78, 38, and 3 AWSs observed rain accumulations in excess of 50, 100, and $300 \mathrm{~mm}$, respectively. The maximum total rainfall was $401.6 \mathrm{~mm}$ (station 3 in Figure 1c), whereas the maximum hourly rainfall accumulation was $184.4 \mathrm{~mm}$ (again station 3). Figure $1 \mathrm{~b}$ shows the average radar reflectivity for 1900-2400 UTC, and Figure 1c shows the average reflectivity enlarged on a local scale. The average reflectivities exceeded $35 \mathrm{dBZ}$ in many places, exceeding $45 \mathrm{dBZ}$ in a narrow area near the radar station. Figure 1a,b clearly show the relatively concentrated spatial and temporal distributions of heavy rain and strong echoes. The locations of those AWSs where the total rainfall exceeded $300 \mathrm{~mm}$ are marked 
with plus signs in Figure 1c, along with the disdrometer (square) at Luogang and the S-band PR (triangle) at Guangzhou.

(a)

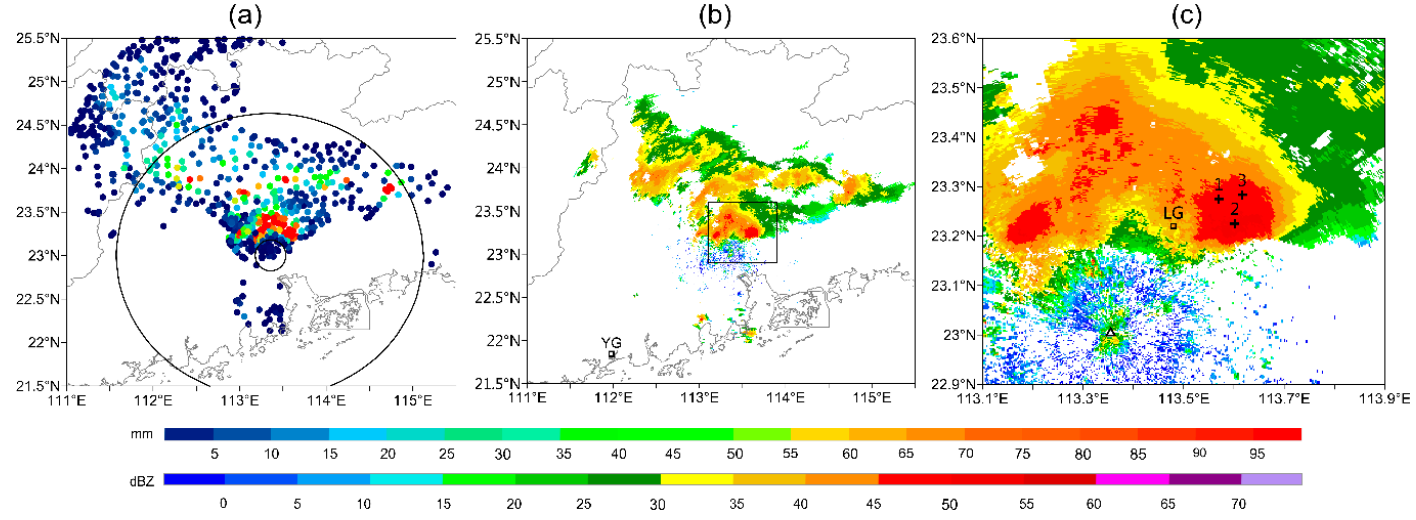

Figure 1. Distributions of (a) total rainfall observed at the automatic weather stations (AWSs) and (b) the average radar reflectivity for 1900-2400 UTC on 6 May 2017; (c) the enlarged area denoted by the square in (b). In (a), precipitation within the area enclosed by circles is evaluated. In (b), the small square indicates the location of the Yangjiang disdrometer $\left(21.84^{\circ} \mathrm{N}, 111.98^{\circ} \mathrm{E}, 90 \mathrm{~m}\right.$ above mean sea level). In (c), the triangle denotes the radar location $\left(23.00^{\circ} \mathrm{N}, 113.36^{\circ} \mathrm{E}, 179 \mathrm{~m}\right)$, the " $+^{\prime \prime}$ symbols indicate the three AWSs $\left(23.28^{\circ} \mathrm{N}, 113.57^{\circ} \mathrm{E}, 75 \mathrm{~m} ; 23.23^{\circ} \mathrm{N}, 113.60^{\circ} \mathrm{E}, 48 \mathrm{~m} ; 23.28^{\circ} \mathrm{N}, 113.62^{\circ} \mathrm{E}, 50 \mathrm{~m}\right)$ where total rainfall exceeded $300 \mathrm{~mm}$, and the small square indicates the location of the disdrometer; LG denotes the Luogang disdrometer $\left(23.22^{\circ} \mathrm{N}, 113.48^{\circ} \mathrm{E}, 71 \mathrm{~m}\right)$.

The laser disdrometer (produced by Beijing Metstar Radar Co., Ltd., Beijing, China) can measure the precipitation particle diameter and terminal fall velocity simultaneously. The particle diameter is divided into 64 classes ranging from 0.2 to $30 \mathrm{~mm}$, and the velocity is divided into 32 classes ranging from 0.2 to $20 \mathrm{~m} / \mathrm{s}$. The temporal resolution is $1 \mathrm{~min}$. Note that the disdrometer was not located in the area of heaviest precipitation.

Updated in 2016, the S-band PR deployed in Guangzhou can measure multiple polarimetric variables such as $Z_{\mathrm{H}}, Z_{\mathrm{DR}}$, and $\Phi_{\mathrm{DP}}$ (differential phase). The radar was calibrated in the factory according to the criterion proposed by China Meteorological Administration (CMA) [27]. After radar construction, a series of tests, such as built-in testing, sun-calibration, and vertical pointed calibration were conducted by the Meteorological Observation Center of CMA. The results of the tests indicated that $Z_{\mathrm{H}}$ accuracy is better than $1 \mathrm{~dB}$ and $Z_{\mathrm{DR}}$ accuracy is better than $0.4 \mathrm{~dB}$. The radar operates in the conventional VCP21 volume-scan mode and completes a volume scan using nine specific elevation angles $\left(0.5^{\circ}, 1.5^{\circ}, 2.4^{\circ}, 3.3^{\circ}, 4.3^{\circ}, 6.0^{\circ}, 9.9^{\circ}, 14.6^{\circ}\right.$, and $\left.19.5^{\circ}\right)$ in $6 \mathrm{~min}$, with a $0.95^{\circ}$ beam width, a $0.25 \mathrm{~km}$ radial resolution and a $460 \mathrm{~km}$ maximum detection range. Figures 2 and 3 show the evolution of reflectivity and radial velocity at $0.5^{\circ}$ elevation during 1900-2400 UTC. At 2000 UTC, strong echoes reached the three AWSs and developed rapidly. During 2000-2300 UTC, echoes larger than 50 dBZ remained there and changed little in reflectivity, location, and influence area. The radial velocities at $0.5^{\circ}$ and $1.5^{\circ}$ elevations (not shown) indicate that gradually intensifying northerly and southerly winds converged at around $560 \mathrm{~m}$ above the ground at 2000 UTC. The convergence area evolved gradually into a convergence belt and reached its maximum convergence at 2200 UTC, resulting in persistent ascending motion leading to persistent strong echoes and heavy rain. 
(a) 6 May 20171900 UTC

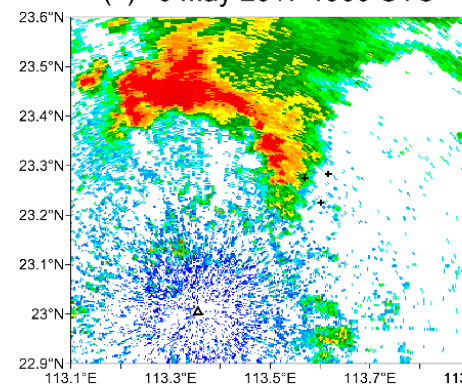

(d) 6 May 20172200 UTC (b) 6 May 20172000 UTC

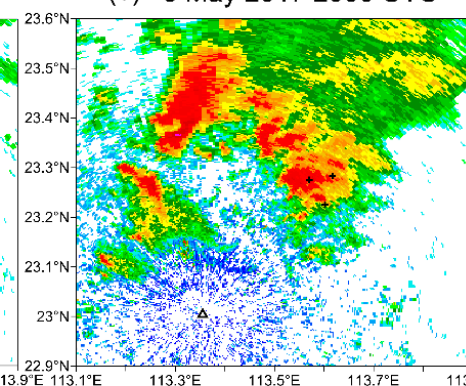

(e) 6 May 20172300 UTC (c) 6 May 20172100 UTC

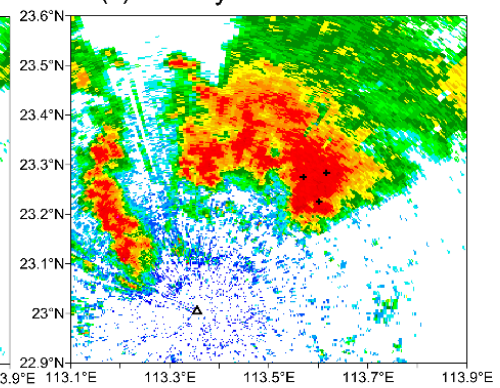

(f) 6 May 20172400 UTC

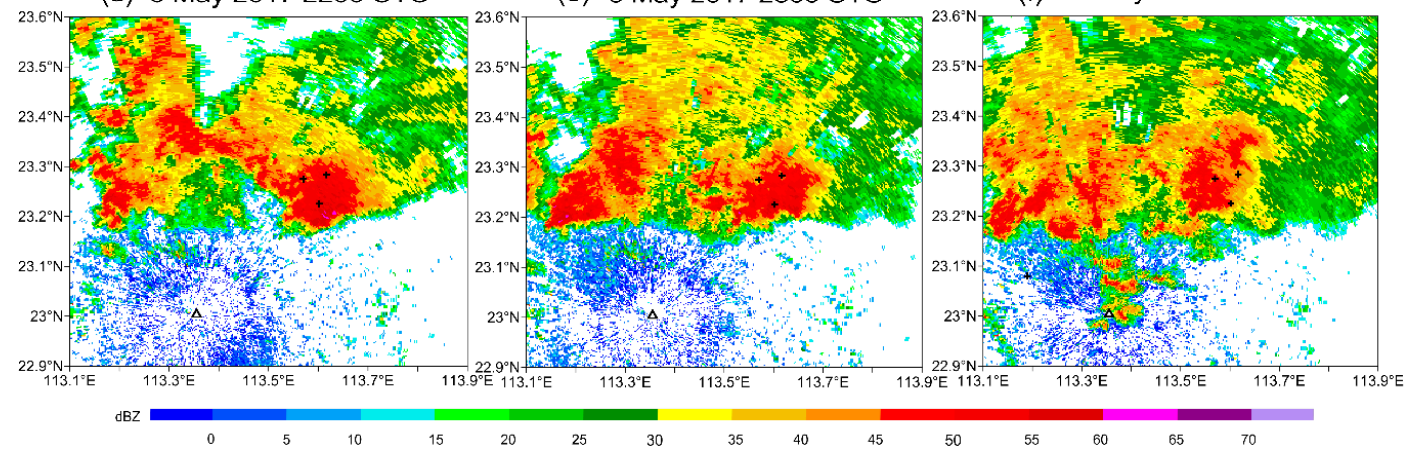

Figure 2. Radar reflectivity at $0.5^{\circ}$ elevation during rainfall event on 6 May 2017: (a) 1900 UTC, (b) 2000 UTC, (c) 2100 UTC, (d) 2200 UTC, (e) 2300 UTC, and (f) 2400 UTC.

(a) 6 May 20171900 UTC

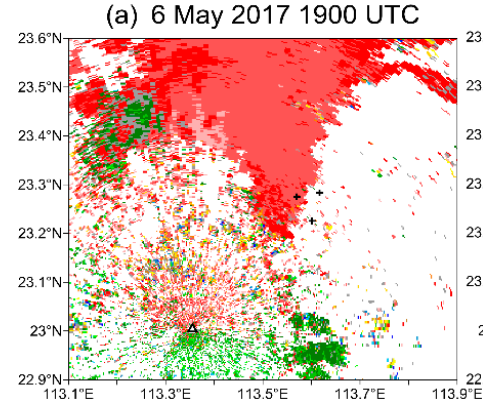

(d) 6 May 20172200 UTC

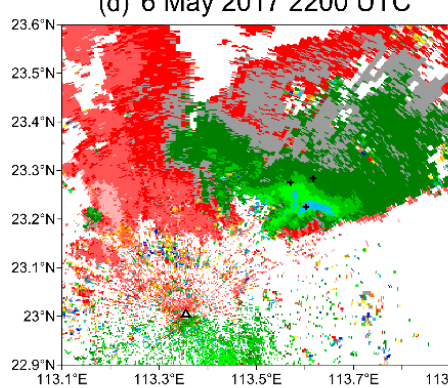

(b) 6 May 20172000 UTC

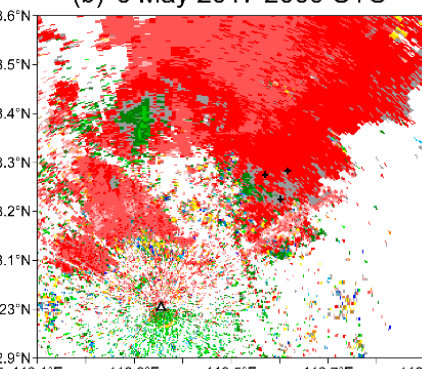

(e) 6 May 20172300 UTC (c) 6 May 20172100 UTC

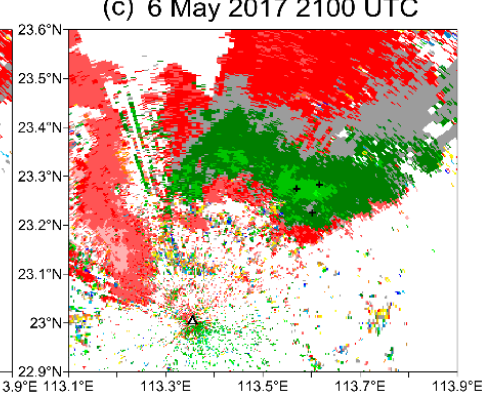

(f) 6 May 20172400 UTC

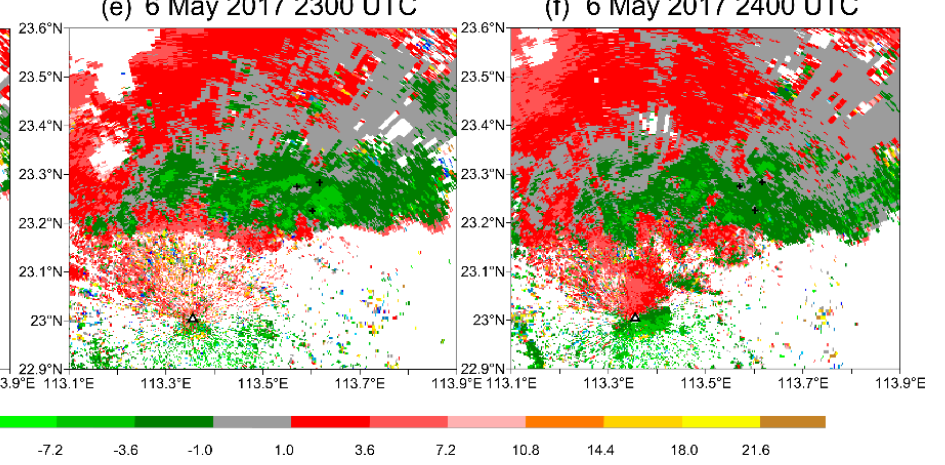

Figure 3. Radial velocity at $0.5^{\circ}$ elevation during rainfall event on 6 May 2017: (a) 1900 UTC, (b) 2000 UTC, (c) 2100 UTC, (d) 2200 UTC, (e) 2300 UTC, and (f) 2400 UTC.

\section{Methods}

\subsection{QPE Algorithm and Evaluation Method}

In this study, we propose a localized PR QPE algorithm that accounts for hydrometeor phase classification (a flowchart is shown in Figure 4). This algorithm is designed for the operational PRs in 
Guangdong, which is practical and easy to implement. Based on data quality, hydrometeor phase type, and polarimetric data threshold, the QPE algorithm is conducted for poor-quality data, mixed-phase precipitation, and liquid precipitation, respectively.

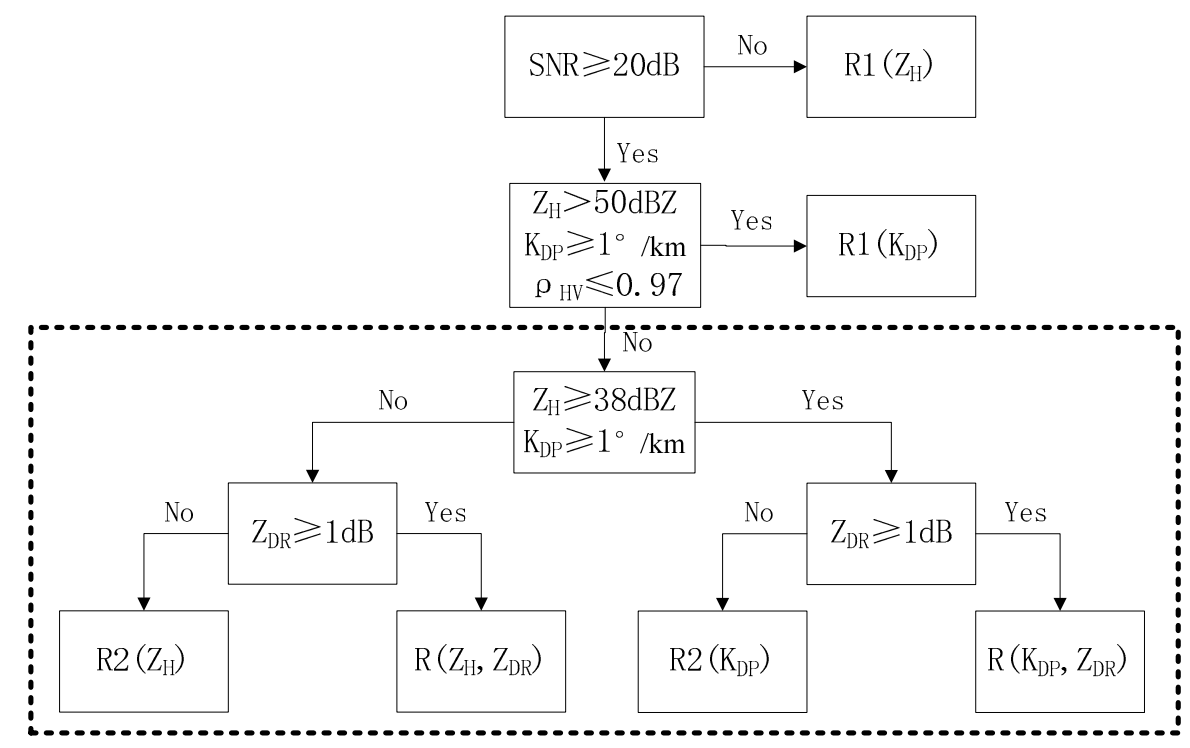

Figure 4. Flowchart describing the precipitation-estimation algorithm.

An analysis of the PR data from China [27] indicates that noise can easily affect $Z_{\mathrm{DR}}$ and $K_{\mathrm{DP}}$ when the $S N R$ is $<20 \mathrm{~dB}$, leading to large spatiotemporal variations. Therefore, under these SNR conditions, $Z_{\mathrm{DR}}$ and $K_{\mathrm{DP}}$ are not appropriate for precipitation estimation, and $R 1\left(Z_{\mathrm{H}}\right)$ is used instead. For mixed-phase precipitation (e.g., hail contamination), because the backscattering cross-section of hail is much larger than that of raindrops, $Z_{\mathrm{H}}$ can be extremely large. Hail rolling results in $Z_{\mathrm{DR}}$ being close to $0 \mathrm{~dB}$, and hail melting results in $Z_{\mathrm{DR}}$ being very large [28]. However, hail makes little contribution to rain accumulation. Previous studies have shown that precipitation estimation used $Z_{\mathrm{H}}$ and $Z_{\mathrm{DR}}$ are not efficient in situations of hail contamination $[3,6,17]$. Because $K_{\mathrm{DP}}$ is immune to hail contamination, rainfall algorithms based on $K_{\mathrm{DP}}$ are more robust in the presence of hail $[3,16]$. In the present study, the mixed-phase precipitation is determined by $Z_{\mathrm{H}}>50 \mathrm{dBZ}, K_{\mathrm{DP}} \geq 1^{\circ} / \mathrm{km}$, and $\rho_{\mathrm{HV}} \leq 0.97$, and its rainfall rate is estimated with $K_{\mathrm{DP}}$ only. The QPE algorithm for liquid precipitation is similar to the CSU-HIDRO algorithm [7], which is denoted by the dashed frame in Figure 4.

The rainfall estimators shown in Figure 4 are expressed by:

$$
\begin{gathered}
R 1,2\left(Z_{\mathrm{H}}\right)=\mathrm{a} Z_{\mathrm{H}}{ }^{\mathrm{b}}, \\
R 1,2\left(K_{\mathrm{DP}}\right)=\mathrm{a} K_{\mathrm{DP}}{ }^{\mathrm{b}}, \\
R\left(Z_{\mathrm{H}}, Z_{\mathrm{DR}}\right)=\mathrm{a} Z_{\mathrm{H}}{ }^{\mathrm{b}} 10^{\mathrm{c} Z_{\mathrm{DR}},} \\
R\left(K_{\mathrm{DP}}, Z_{\mathrm{DR}}\right)=\mathrm{a} K_{\mathrm{DP}}{ }^{\mathrm{b}} 10^{\mathrm{c} Z_{\mathrm{DR}},}
\end{gathered}
$$

where $Z_{\mathrm{H}}$ is in units of $\mathrm{mm}^{6} / \mathrm{m}^{3}, Z_{\mathrm{DR}}$ is in $\mathrm{dB}, K_{\mathrm{DP}}$ is in ${ }^{\circ} / \mathrm{km}$, and $R$ is in $\mathrm{mm} / \mathrm{h}$.

The coefficients of $R 1\left(Z_{\mathrm{H}}\right)$ and $R 2\left(Z_{\mathrm{H}}\right)$ are different. $R 1\left(Z_{\mathrm{H}}\right)$ is used for light rain, and $R 2\left(Z_{\mathrm{H}}\right)$ is used for moderate rain with low $Z_{\mathrm{DR}}$ and $K_{\mathrm{DP}}$. The coefficients of $R 1\left(K_{\mathrm{DP}}\right)$ and $R 2\left(K_{\mathrm{DP}}\right)$ are also different. $R 1\left(K_{\mathrm{DP}}\right)$ is applied to mixed-phase precipitation, whereas $R 2\left(K_{\mathrm{DP}}\right)$ is applied to liquid precipitation.

The coefficients used in Equations (1)-(4) were obtained from the DSD data for 27 April to 11 June 2014 from Yangjiang in Guangdong (shown in Figure 1b) [7,29]. Note that the DSD data used for fitting should be chosen according to the thresholds used for the rainfall estimators. For example, 
DSD data that satisfy $Z_{\mathrm{H}}>50 \mathrm{dBZ}$ and $K_{\mathrm{DP}} \geq 1^{\circ} / \mathrm{km}$ are used to fit $R 1\left(K_{\mathrm{DP}}\right)$. The coefficients of the rainfall estimators shown in Figure 4 are given in Table 1.

Table 1. Coefficients of quantitative precipitation-estimation algorithm.

\begin{tabular}{cccc}
\hline Coefficient & $\mathbf{a}$ & $\mathbf{b}$ & $\mathbf{c}$ \\
\hline$R 1\left(Z_{\mathrm{H}}\right)$ & 0.0082 & 0.7490 & \\
$R 2\left(Z_{\mathrm{H}}\right)$ & 0.0154 & 0.7681 & \\
$R 1\left(K_{\mathrm{DP}}\right)$ & 30.30 & 0.9298 & \\
$R 2\left(K_{\mathrm{DP}}\right)$ & 34.56 & 0.9496 & \\
$R\left(Z_{\mathrm{H}}, Z_{\mathrm{DR}}\right)$ & 0.0084 & 0.9284 & -0.4055 \\
$R\left(K_{\mathrm{DP}}, \mathrm{Z}_{\mathrm{DR}}\right)$ & 51.16 & 0.9311 & -0.0852 \\
\hline
\end{tabular}

Radar bins within 20-35, 35-60, and 60-180 km from the radar station in the plan position indicator (PPI) at elevation angles of $2.4^{\circ}, 1.5^{\circ}$, and $0.5^{\circ}$, respectively, are used to estimate the precipitation. To avoid the influences of the melting layer and the ground clutter, for evaluation, we used 558 AWSs that are within $20-180 \mathrm{~km}$ from the radar location. They are distributed between the two circles shown in Figure 1a.

We used the rain rate produced by the S-band PR at a temporal resolution of 6 min to calculate hourly rainfall accumulations, taking the rainfall accumulations measured at the AWSs as true accumulations. We used the average radar-estimated precipitation of the nine radar bins nearest to an AWS to evaluate the QPE performance. Because the AWS resolution is $0.1 \mathrm{~mm}$, only rainfall measurements that exceeded $0.1 \mathrm{~mm}$ were used for evaluation. As statistical indicators of algorithmic performance, we obtained the correlation coefficient (CC), root mean square error (RMSE), normalized relative bias $(N B)$, normalized absolute error $(N E)$, the bias ratio of radar-estimated rainfall to AWS-observed rainfall (bias ratio), and Nash-Sutcliffe efficiency score (Eff), which are defined as:

$$
\begin{gathered}
C C=\frac{\sum_{i=1}^{n}\left(R A_{i}^{\text {radar }}-\overline{R A_{i}^{\text {radar }}}\right)\left(R A_{i}^{\text {gauge }}-\overline{R A_{i}^{\text {gauge }}}\right)}{\sqrt{\sum_{i=1}^{n}\left(R A_{i}^{\text {radar }}-\overline{R A_{i}^{\text {radar }}}\right)^{2} \sum_{i=1}^{n}\left(R A_{i}^{\text {gauge }}-\overline{R A_{i}^{\text {gauge }}}\right)^{2}}}, \\
R M S E=\sqrt{\frac{\sum_{i=1}^{n}\left(R A_{i}^{\text {radar }}-R A_{i}^{\text {gauge }}\right)^{2}}{n}}, \\
N B=\frac{\sum_{i=1}^{n}\left(R A_{i}^{\text {radar }}-R A_{i}^{\text {gauge }}\right)}{\sum_{i=1}^{n} R A_{i}^{\text {gauge }}} \times 100, \\
N E=\frac{\sum_{i=1}^{n}\left|R A_{i}^{\text {radar }}-R A_{i}^{\text {gauge }}\right|}{\sum_{i=1}^{n} R A_{i}^{\text {gauge }}} \times 100, \\
\text { bias } \quad \text { ratio }=\frac{\sum_{i=1}^{n} R A_{i}^{\text {radar }}}{\sum_{i=1}^{n} R A_{i}^{\text {gauge }}},
\end{gathered}
$$




$$
E f f=1-\frac{\sum_{i=1}^{n}\left(R A_{i}^{\text {gauge }}-R A_{i}^{\text {radar }}\right)^{2}}{\sum_{i=1}^{n}\left(R A_{i}^{\text {gauge }}-\overline{R A_{i}^{\text {gauge }}}\right)^{2}},
$$

where $R A$ is accumulation from either radar or an AWS gauge, an overbar represents a mean value, $n$ is the number of $R A_{\mathrm{i}}$ gauge $-R_{\mathrm{i}}{ }^{\text {radar }}$ pairs, $R M S E$ is in millimeters, and NE and NB are both percentages. A bias ratio larger (resp. smaller) than one indicates overestimation (resp. underestimation). Eff is a statistical measure of the variability of the error normalized by the natural variability of the estimated parameter and is scaled from $-\infty$ to 1 . A value of one indicates that the estimate is perfect. An efficiency value equal to 0 or negative indicates that the estimation is, respectively, no better or even worse than using simply the mean value of the observations [30].

\subsection{Rain Microphysics Retrieval Algorithm}

To analyze the factors affecting QPE, several rain variables need to be derived from PR observations. The DSD model used in the simulations is the normalized gamma distribution $N(\mathrm{D})[31,32]:$

$$
\begin{gathered}
N(D)=N_{\mathrm{w}} f(\mu)\left(\frac{D}{D_{\mathrm{m}}}\right)^{\mu} \exp \left[-(u+4) \frac{D}{D_{\mathrm{m}}}\right], \\
f(\mu)=\frac{6}{4^{4}} \frac{(4+\mu)^{\mu+4}}{\Gamma(\mu+4)},
\end{gathered}
$$

where the parameter $\mu$ is a measure of the shape of the gamma DSD, and $f(\mu)$ is a unitless function of $\mu$. $\Gamma$ is the gamma function. $N_{\mathrm{w}}\left(\mathrm{mm}^{-1} \mathrm{~m}^{-3}\right)$ is a normalized intercept parameter, and the parameter $D_{\mathrm{m}}(\mathrm{mm})$ is the mass-weighted mean diameter. $N_{\mathrm{w}}$ and $D_{\mathrm{m}}$ can be expressed as

$$
\begin{gathered}
N_{\mathrm{w}}=\frac{4^{4}}{\pi \rho_{\mathrm{w}}}\left(\frac{10^{3} \mathrm{~W}}{D_{\mathrm{m}}^{4}}\right), \\
W=\frac{\pi}{6000} \sum_{i=1}^{32} N\left(D_{i}\right) D_{i}^{3} \Delta D_{i}, \\
D_{\mathrm{m}}=\frac{E\left(D^{4}\right)}{E\left(D^{3}\right)},
\end{gathered}
$$

where the water content $W$ is in $\mathrm{g} \mathrm{m}^{-3}$, the water density $\rho_{\mathrm{w}}$ is in $\mathrm{g} \mathrm{cm}^{-3}$, and $E$ represents the expected value. Moment methods have been widely used to estimate these parameters for cloud and precipitation in numerical models [33]. The third, fourth, and sixth moments of the DSD data are used to estimate $\mu, N_{\mathrm{w}}$, and $D_{\mathrm{m}}$.

Bringi et al. [34] proposed using polarimetric radar measurements of $Z_{\mathrm{H}}, Z_{\mathrm{DR}}$, and $K_{\mathrm{DP}}$ to retrieve a normalized gamma DSD. However, Brandes et al. [35] showed that this approach is sensitive to $K_{\mathrm{DP}}$ noise. In addition, $K_{\mathrm{DP}}$ is derived from measurements made over many range gates and does not always match $Z_{\mathrm{H}}$ and $Z_{\mathrm{DR}}$ measurements well at every range gate. Therefore, the addition of $K_{\mathrm{DP}}$ may result in a deterioration of the DSD retrieval at a specific range gate, especially if it is not used optimally [36]. Because the three parameters of the gamma DSD distribution are not mutually independent, two PR variables can be used to retrieve the rain variables $\left(D_{\mathrm{m}}\right.$ and $\left.N_{\mathrm{w}}\right)$ [36]. In this study, only $Z_{\mathrm{H}}$ and $Z_{\mathrm{DR}}$ are used to retrieve rain variables. Cao et al. [37] and Brandes et al. [35] used a constraining $\mu-\Lambda$ relation to derive the relationships between rain variables and radar variables. However, errors may propagate through this procedure [36]. Fitting directly with observations can reduce error propagation. According to the method described by Cao et al. [36], a sorting and averaging procedure based on two parameters (SATP) is introduced to mitigate the effects of sampling errors on DSD fitting. Based on Yangjiang historical DSD data processed with the SATP method, $Z_{\mathrm{H}}, Z_{\mathrm{DR}}$, $D_{\mathrm{m}}$, and $N_{\mathrm{w}}$ were calculated for each data point. Using a three-order polynomial fit described by 
Cao et al. [36] for all data points, rain variables were expressed in terms of radar variables as (see also Figure $5 a, b)$ :

$$
\begin{gathered}
D_{\mathrm{m}}=0.0834 Z_{\mathrm{DR}}^{3}-0.391 Z_{\mathrm{DR}}^{2}+1.425 Z_{\mathrm{DR}}+0.39, \\
\left\{\begin{array}{ll}
N_{\mathrm{w}}=Z_{\mathrm{H}} \times 10^{-3.4026 Z_{\mathrm{DR}}^{3}+8.1785 Z_{\mathrm{DR}}^{2}-8.8336 Z_{\mathrm{DR}}+4.2035} & Z_{\mathrm{DR}}<1 \\
N_{\mathrm{w}}=Z_{\mathrm{H}} \times 10^{-0.1416 Z_{\mathrm{DR}}^{3}+0.9153 Z_{\mathrm{DR}}^{2}-3.0924 Z_{\mathrm{DR}}+2.4730} & Z_{\mathrm{DR}} \geq 1
\end{array},\right.
\end{gathered}
$$

where $Z_{\mathrm{H}}$ is in $\mathrm{mm}^{6} \mathrm{~m}^{-3}$, and $Z_{\mathrm{DR}}$ is in $\mathrm{dB}$. CC and $\mathrm{NB}$ between retrieval values and observed values were calculated based on Equations (5) and (7), respectively, which are shown in Figure 5. The two variables have a small NB and a CC close to 1 . These results indicate that the relationships between the rain variables $\left(D_{\mathrm{m}}\right.$ and $\left.N_{\mathrm{w}}\right)$ and radar variables $\left(Z_{\mathrm{H}}\right.$ and $\left.Z_{\mathrm{DR}}\right)$ in Equations (16) and (17) are valid for the rain DSD retrieval.

(a)

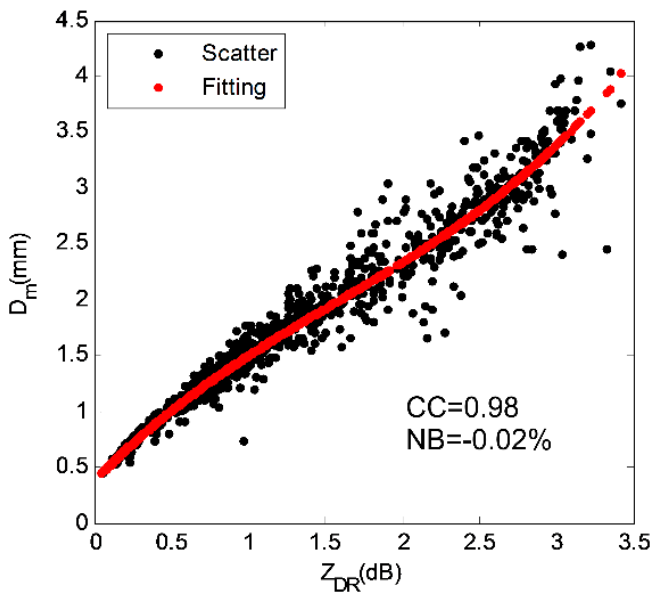

(b)

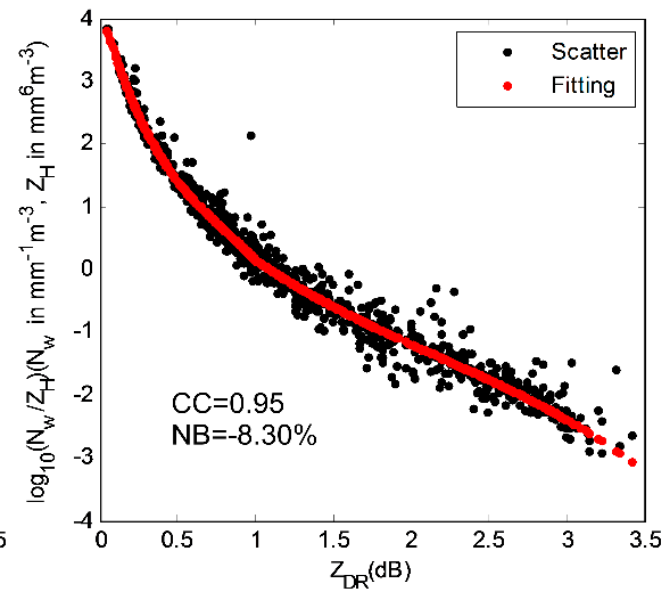

Figure 5. Scatterplots of rain variables $\left(D_{\mathrm{m}}\right.$ and $\left.N_{\mathrm{w}}\right)$ and radar variables $\left(Z_{\mathrm{H}}\right.$ and $\left.Z_{\mathrm{DR}}\right)$ calculated from drop size distribution (DSD) data. The red points are mean data value, which are fitted to the black data points by using a three-order polynomial fit with the least-squares method. (a) $D_{\mathrm{m}}$ vs. $Z_{\mathrm{DR}}$ (Equation (16)), and (b) ratio of $N_{\mathrm{w}}$ to $Z_{\mathrm{H}}$ vs. $Z_{\mathrm{DR}}$ (Equation (17)). Correlation coefficient (CC) and normalized relative bias (NB) for the retrieved rain variables versus the observations are shown in this figure.

\section{Result}

In this section, nine rainfall events that occurred in Guangzhou in 2016 were chosen to examine the QPE algorithm for the operational PRs in Guangdong. The extremely heavy rainfall event that occurred in Guangzhou on 6 May 2017 was used to test the capability of the algorithm to estimate heavy precipitation.

\subsection{Algorithm Performance for the Nine Rainfall Events}

Table 2 shows the nine rainfall events that occurred in Guangzhou. These events include stratocumulus and convective precipitation, and several convective precipitation events are squall line events.

The evaluated statistical scores for QPE of the nine rainfall events are shown in Table 3. For all nine rainfall events, NE ranges from $35.20 \%$ to $43.75 \%$, NB ranges from $-17.20 \%$ to $15.19 \%$, and Eff ranges from 0.68 to 0.78 . Although some underestimations or overestimations of rainfall occurred in some rainfall events, the performance of the algorithm is good for all $24,755 R A_{i}{ }^{\text {gauge }}-R_{i}{ }^{\text {radar }}$ pairs from all nine rainfall events in terms of NB, which is close to zero (shown in Table 4). Besides NB, the other evaluated statistical scores shown in Table 4 are also satisfied for the total data pairs. The algorithm performance is also good for light-to-moderate rain. However, the algorithm severely underestimated heavy rain 
(hourly rainfall accumulation $>50 \mathrm{~mm}$ ). Fortunately, heavy rain pairs are very few, accounting for only $0.26 \%$ of the total pairs.

Table 2. A list of the nine rainfall events analyzed in this study.

\begin{tabular}{ccccccc}
\hline$\#$ & Date (UTC) & $\begin{array}{c}\text { Total } \\
\text { Time } \\
\text { (h) }\end{array}$ & $\begin{array}{c}\text { No. of } \\
\text { Valued } \\
\text { Gauges }\end{array}$ & $\begin{array}{c}\text { Mean Gauge } \\
\text { Accumulation } \\
(\mathbf{m m})\end{array}$ & $\begin{array}{c}\text { Max Gauge } \\
\text { Accumulation } \\
(\mathbf{m m})\end{array}$ & $\begin{array}{c}\text { Precipitation } \\
\text { Type }\end{array}$ \\
\hline 1 & 6 May 2016 & 12 & 284 & 19.60 & 52.4 & squall line \\
2 & 9-10 May 2016 & 34 & 383 & 43.92 & 134.8 & convective \\
3 & 15 May 2016 & 10 & 380 & 16.79 & 67.2 & squall line \\
4 & 19-21 May 2016 & 43 & 384 & 70.01 & 223.5 & stratocumulus \\
5 & 27-28 May 2016 & 24 & 382 & 37.19 & 207.5 & squall line \\
6 & 4-5 June 2016 & 24 & 386 & 33.84 & 90.2 & stratocumulus \\
7 & 9 June 2016 & 8 & 143 & 13.02 & 80.2 & stratocumulus \\
8 & 11-14 June 2016 & 86 & 396 & 59.04 & 237.4 & stratocumulus \\
9 & 15 June 2016 & 6 & 211 & 13.64 & 45.2 & squall line \\
\hline
\end{tabular}

Table 3. Evaluated statistical scores for quantitative precipitation estimation (QPE) of the nine rainfall events.

\begin{tabular}{ccccccc}
\hline$\#$ & CC & RMSE (mm) & NE (\%) & NB (\%) & Eff & NUM \\
\hline 1 & 0.87 & 4.57 & 35.20 & 3.85 & 0.75 & 722 \\
2 & 0.88 & 4.59 & 37.90 & -6.36 & 0.77 & 2795 \\
3 & 0.86 & 4.16 & 38.85 & 1.35 & 0.74 & 1097 \\
4 & 0.88 & 3.33 & 38.44 & -17.20 & 0.75 & 6176 \\
5 & 0.89 & 3.65 & 40.65 & 0.12 & 0.78 & 3380 \\
6 & 0.87 & 2.89 & 41.02 & 15.19 & 0.71 & 3357 \\
7 & 0.85 & 3.08 & 43.07 & 3.62 & 0.68 & 498 \\
8 & 0.87 & 3.60 & 43.75 & 10.92 & 0.75 & 6212 \\
9 & 0.85 & 3.57 & 39.05 & 7.00 & 0.70 & 518 \\
\hline
\end{tabular}

Table 4. Evaluated statistical scores for QPE of the nine total rainfall events.

\begin{tabular}{cccccccc}
\hline Hourly Accumulation & CC & RMSE (mm) & NE (\%) & NB (\%) & Eff & Bias Ratio & NUM \\
\hline total & 0.87 & 3.63 & 40.02 & -0.33 & 0.76 & 1.00 & 24,755 \\
$<50 \mathrm{~mm}$ & 0.87 & 3.42 & 40.26 & 0.57 & 0.75 & 1.01 & 24,691 \\
$>50 \mathrm{~mm}$ & 0.29 & 24.12 & 33.31 & -30.58 & -6.60 & 0.69 & 64 \\
\hline
\end{tabular}

The operational algorithm presented in this study was also compared with two mature operational radar systems. Multi-Radar Multi-Sensor (MRMS) is a comprehensive system operated by the American National Weather Service that combines data streams from multiple radars, satellites, surface observations, upper air observations, lightning reports, rain gauges, and numerical weather prediction models to produce a suite of decision-support products. MRMS polarimetric radar QPE product performance was evaluated for the data collected east of the Rockies during the 2014 warm season [38]. Below the melting layer, the bias ratio is 1.06, which is slightly larger than that of the algorithm presented in this study. The other operational radar system is from France. For the evaluation at S-band, two precipitation events observed by the Nimes radar in 2010 are analyzed [39]. NB and RMSE for the optimal polarimetric algorithm are $-9 \%$ and $8.46 \mathrm{~mm}$, respectively, for the intense rain (hourly accumulations $>5 \mathrm{~mm}$ ). Compared with it, the algorithm presented in this study is slightly better in terms of identical NB (-9\%) and lower RMSE $(6.55 \mathrm{~mm})$ for the intense rain. These comparisons show that the performance of the operational algorithm in this study is good.

\subsection{Algorithm Performance for This Extremely Heavy Rainfall Event}

The maximum total rainfall of the heaviest rainfall event listed in Table 2 was $207.54 \mathrm{~mm}$ within $24 \mathrm{~h}$. However, the maximum total rainfall of the rainfall event that occurred on 6 May 2017 was 
$401.6 \mathrm{~mm}$ in only $5 \mathrm{~h}$. It is a great challenge to estimate this rainfall with PR. To examine the capability to estimate extremely heavy rain, the algorithm presented in this study was applied to estimate precipitation during this extremely heavy rainfall event. Table 5 lists the evaluated statistical scores for the QPE at various hourly accumulations. There are 1341 samples of data pairs in all. Data pairs are divided into two classes to evaluate light-to-moderate rain $(<50 \mathrm{~mm})$ and heavy rain. The results indicate that the algorithm performs well for the light-to-moderate rain in terms of NB, which is close to 0 . However, the performance for heavy rain is poor and the algorithm heavily underestimated the heavy rain.

Table 5. Evaluated statistical scores for the QPE of this rainfall event.

\begin{tabular}{ccccccc}
\hline Hourly Accumulation & CC & RMSE (mm) & NE (\%) & NB (\%) & Eff & NUM \\
\hline total & 0.88 & 7.48 & 37.61 & -7.20 & 0.77 & 1341 \\
$<50 \mathrm{~mm}$ & 0.84 & 5.67 & 39.81 & -0.40 & 0.67 & 1301 \\
$>50 \mathrm{~mm}$ & 0.68 & 28.84 & 30.40 & -29.43 & -0.21 & 40 \\
\hline
\end{tabular}

Figure 6 shows the hourly radar or gauge rainfall accumulations at the three AWSs where the total rainfall exceeded $300 \mathrm{~mm}$. Hours 1-5 correspond to 1900-2000 UTC, 2000-2100 UTC, 2100-2200 UTC, 2200-2300 UTC, and 2300-2400 UTC, respectively. A similar scenario occurred at all three stations. The QPE algorithm underestimated the rainfall for hourly rainfall accumulations $>50 \mathrm{~mm}$, especially at station 2 where the maximum hourly rainfall accumulation occurred.
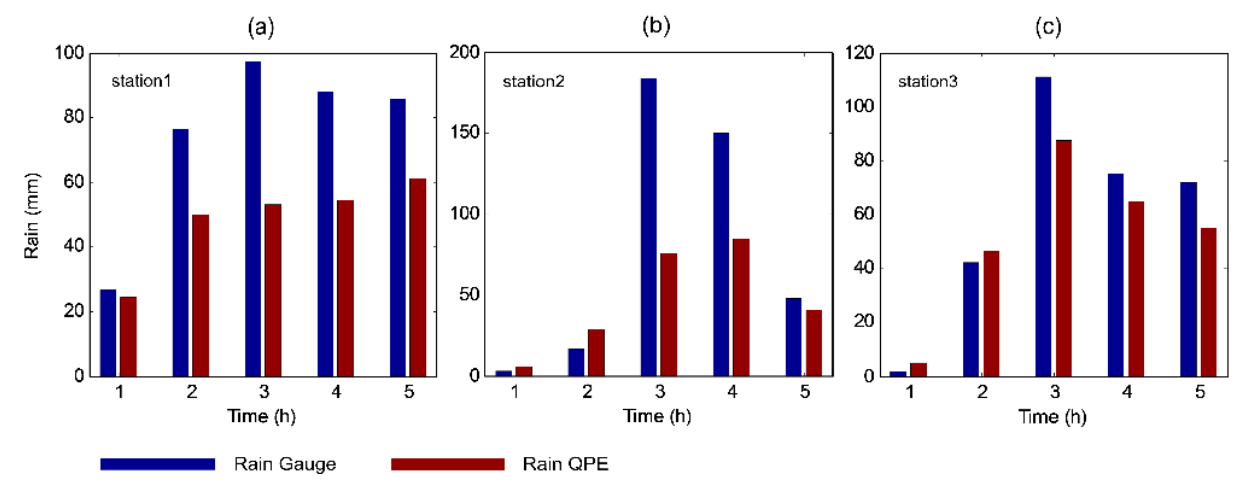

Figure 6. Hourly rainfall accumulations at stations where the largest rainfall accumulations were observed. (a-c) show the QPE results of the algorithm at stations 1-3, respectively. The column in blue indicates an AWS observation, and the column in red indicates the radar estimate.

In general, regarding NB, the QPE algorithm performs better for light-to-moderate rain, but it underestimates heavy rain. The same pertains to the three stations where the heaviest rainfall occurred.

\section{Analysis of Factors Affecting QPE}

\subsection{DSD Characteristics in This Rainfall Event and Their Effects on QPE}

As shown in Figure 7, we obtained the occurrence frequencies of $Z_{\mathrm{DR}}$ versus $Z_{\mathrm{H}}$ and $K_{\mathrm{DP}}$ versus $Z_{\mathrm{H}}$ based on a statistical analysis of the $Z_{\mathrm{H}}-Z_{\mathrm{DR}}$ and $Z_{\mathrm{H}}-K_{\mathrm{DP}}$ observations below $3 \mathrm{~km}$ (for $Z_{\mathrm{DR}}>1 \mathrm{~dB}$, $S N R>20 \mathrm{~dB}$ and $K_{\mathrm{DP}}>1^{\circ} / \mathrm{km}, S N R>20 \mathrm{~dB}$ ). To analyze the DSD characteristics in this rainfall event, besides DSD data collected at Yangjiang during April-June 2014, we also used another set of DSD data collected at Luogang during this rainfall event from 1600 UTC, 6 May 2017 to 1600 UTC, 7 May 2017. DSD data collected during April-June 2014 were compared with DSD data collected during the target rainfall event. We calculated $Z_{\mathrm{H}}, Z_{\mathrm{DR}}$, and $K_{\mathrm{DP}}$ based on these DSDs and then averaged them to obtain the curves shown in Figure 7, which represent the statistical (i.e., average) microphysical properties of 
precipitation in this region (black curve) and the specific microphysical properties of precipitation for this rainfall event (red curve). Note that the black curve and the QPE estimators are from the same DSD sources.

(a)

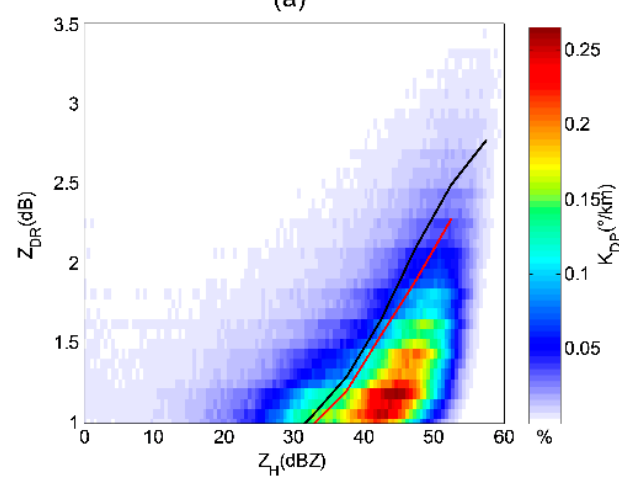

(b)

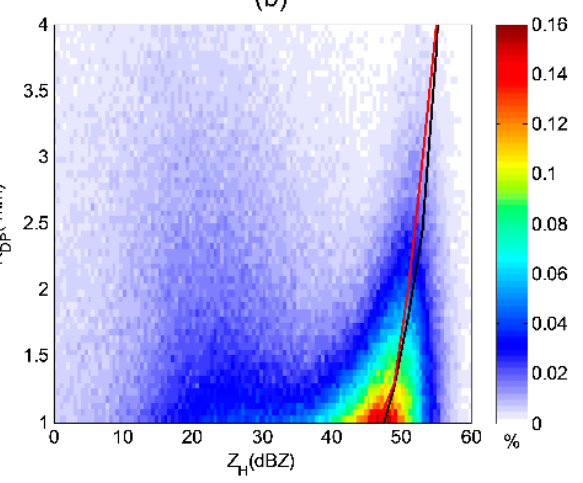

Figure 7. Occurrence frequencies of (a) $Z_{\mathrm{DR}}$ versus $Z_{\mathrm{H}}$ and (b) $K_{\mathrm{DP}}$ versus $Z_{\mathrm{H}}$ from polarimetric radar. The average $Z_{\mathrm{DR}}-Z_{\mathrm{H}}$ and $K_{\mathrm{DP}}-Z_{\mathrm{H}}$ relationships were calculated from DSDs at the Yangjiang (black curves) and Luogang stations (red curves) for this rainfall event.

Comparing the curves in Figure $7, Z_{\mathrm{DR}}$ is smaller and $K_{\mathrm{DP}}$ is slightly larger for the same $Z_{\mathrm{H}}$ in this rainfall event, indicating there is a slightly higher concentration of smaller raindrops in this rainfall event than the statistical microphysical properties of precipitation in Yangjiang. Theoretically, the closer the high occurrence frequencies in Figure $7 \mathrm{a}, \mathrm{b}$ are to the black curve, the less-biased the precipitation estimates, and vice versa. The large difference between the high frequencies of $Z_{\mathrm{H}}-Z_{\mathrm{DR}}$ and the black curve suggests that compared with the statistical microphysical properties of precipitation in Yangjiang, the average reflectivity is larger, the raindrops are smaller, and the number concentration is higher in this rainfall event. The large difference also suggests that there probably are some large QPE biases.

The average values of $D_{\mathrm{m}}$ and $\log _{10} N_{\mathrm{w}}$ represent the DSD characteristics more directly. According to the rain microphysics retrieval algorithm presented in Section 3.2, $D_{\mathrm{m}}$ and $\log _{10} N_{\mathrm{w}}$ are retrieved from PR observations. They are also compared with those retrieved from the DSD data observed at the Luogang disdrometer station (Figure 8). Even though there are some slight underestimations or overestimations of $D_{\mathrm{m}}$ and $\log _{10} N_{\mathrm{W}}$, the mean biases are small, namely $-0.03 \mathrm{~mm}$ and $0.15 \mathrm{~dB}$, respectively. This indicates that the $D_{\mathrm{m}}$ and $\log _{10} N_{\mathrm{w}}$ retrieved from the PR observations are reliable.

(a)

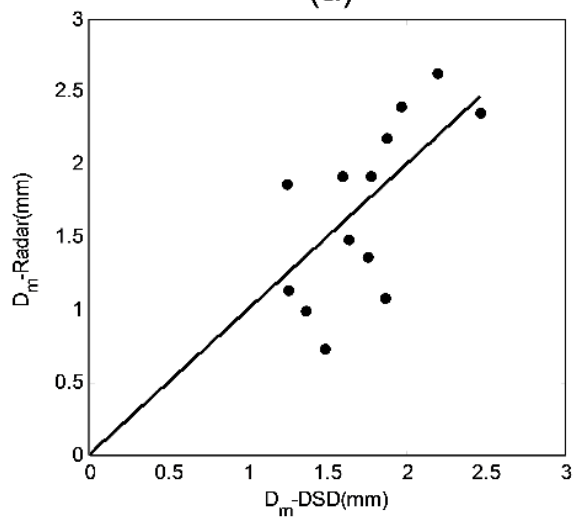

(b)

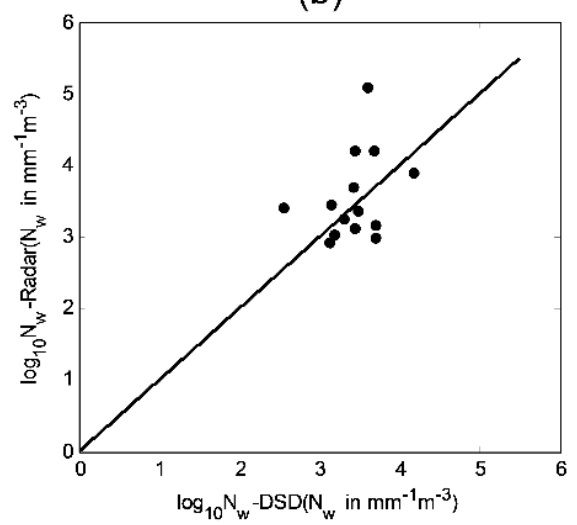

Figure 8. (a) $D_{\mathrm{m}}$ retrieved from radar observations versus DSD data. (b) $\log _{10} N_{\mathrm{w}}$ retrieved from radar observations versus DSD data. 
The occurrence frequencies of $\log _{10} N_{\mathrm{W}}$ versus $D_{\mathrm{m}}$ retrieved from PR observations above the AWSs are shown in Figure 9a. The maritime and continental convective clusters reported by Bringi et al. [40] are also shown in Figure 9a with two black rectangles. Yangiiang DSD data for convective precipitation are used to calculate the average values of $D_{\mathrm{m}}$ and $\log _{10} N_{\mathrm{w}}$, which is shown in Figure 9a with the red " $x$ " symbol. The method to separate stratiform and convective rain types is based on the standard deviation of rain rate over 5 consecutive DSD samples, which are 2-min averaged DSD samples [40]. If this standard deviation is $\leq 1.5 \mathrm{mmh}^{-1}$ then it is classified as stratiform, otherwise it is assumed to be convective. Finally, the average $\log _{10} N_{\mathrm{w}}(3.54)$ and $D_{\mathrm{m}}(1.90 \mathrm{~mm})$ of data retrieved from Yangjiang DSD data for convective precipitation are obtained. Relatively higher values of $D_{\mathrm{m}}$ but lower values of $\log _{10} N_{\mathrm{w}}$ are observed compared with the maritime-like cluster. This is likely associated with high moisture contents and sea salt aerosols.

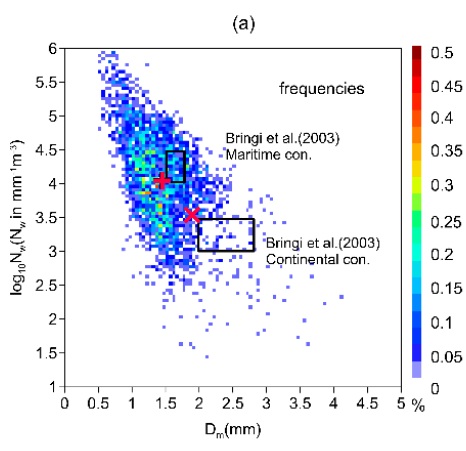

(d)

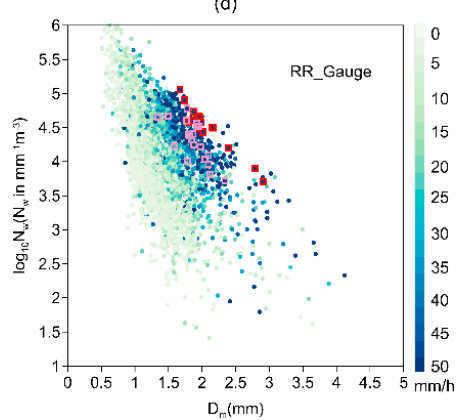

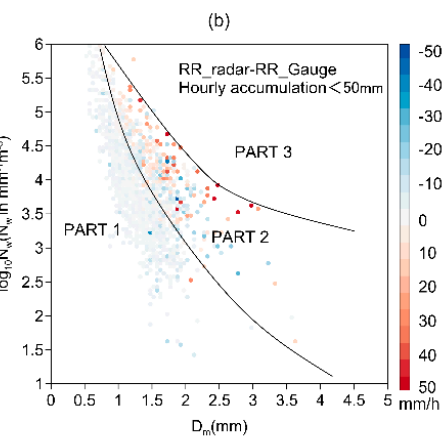

(e)

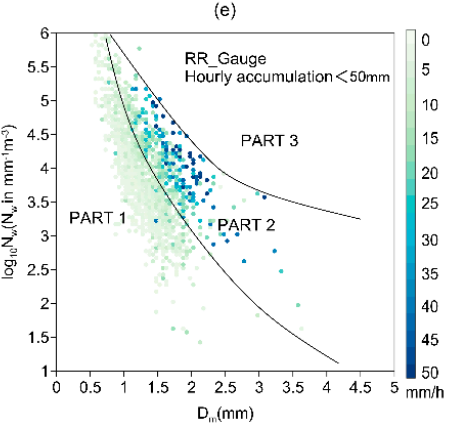

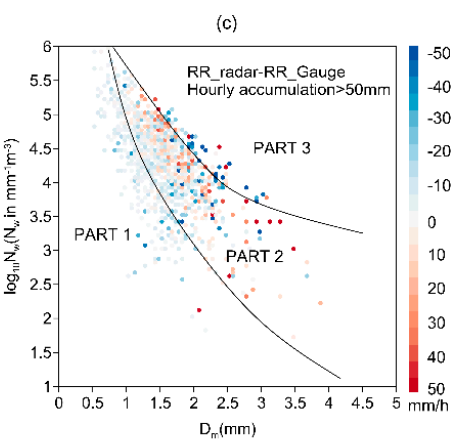

(f)

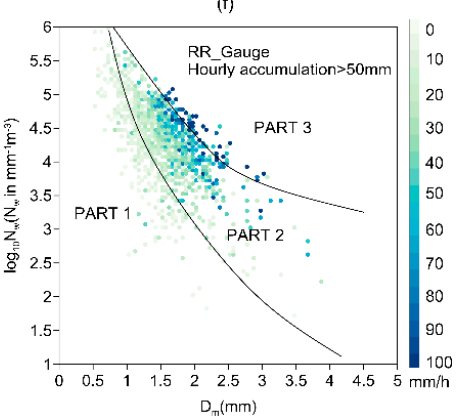

Figure 9. (a) Occurrence frequencies of $\log _{10} N_{\mathrm{w}}$ versus $D_{\mathrm{m}}$. Two black rectangles correspond to the maritime and continental convective clusters, respectively, reported by Bringi et al. [40]. The red " + " symbol indicates the average value of $\log _{10} N_{\mathrm{w}}(4.06)$ and $D_{\mathrm{m}}(1.44 \mathrm{~mm})$ retrieved from radar data and the red " $\times$ " symbol indicates the average value of $\log _{10} N_{\mathrm{w}}(3.54)$ and $D_{\mathrm{m}}(1.90 \mathrm{~mm})$ retrieved from Yangjiang DSD data for convective precipitation. (b) The bias between rain rate retrieved from radar data and rain rate observed at AWSs of $\log _{10} N_{\mathrm{w}}$ versus $D_{\mathrm{m}}$ for hourly accumulation $<50 \mathrm{~mm}$. (c) Biases for hourly accumulation $>50 \mathrm{~mm}$. (d) Rain rate observed at AWSs of $\log _{10} N_{\mathrm{W}}$ versus $D_{\mathrm{m}}$. The pink rectangles indicate rain rate observed at station 1 during 2000-2400 UTC on 6 May 2017 and the red rectangles indicate rain rate observed at station 2 during 2100-2300 UTC on 6 May 2017 and that observed at station 3 during 2200-2300 UTC on 6 May 2017, during which underestimations occurred in each corresponding station. (e) Rain rate observed at AWSs of $\log _{10} N_{\mathrm{W}}$ versus $D_{\mathrm{m}}$ for hourly accumulation $<50 \mathrm{~mm}$. (f) Rain rate observed at AWSs of $\log _{10} N_{\mathrm{W}}$ versus $D_{\mathrm{m}}$ for hourly accumulation $>50 \mathrm{~mm}$. Note that all these data are averaged from two adjacent data in time (average time: $12 \mathrm{~min}$ ).

However, $D_{\mathrm{m}}$ and $N_{\mathrm{W}}$ in this rainfall event are different compared with Yangiiang data. $D_{\mathrm{m}}$ and $N_{\mathrm{W}}$ are retrieved from the polarimetric parameters $Z_{\mathrm{H}}$ and $Z_{\mathrm{DR}}$ based on Equations (16) and (17). $D_{\mathrm{m}}$ mostly ranges from $0.75 \mathrm{~mm}$ to $2.5 \mathrm{~mm}$ and $\log _{10} N_{\mathrm{W}}$ mostly ranges from 2.5 to 5.5 . The average values of $D_{\mathrm{m}}$ and $\log _{10} N_{\mathrm{w}}$ are $1.44 \mathrm{~mm}$ and 4.06, respectively. Compared with the values of data derived from the Yangjiang DSD data, the average value of $D_{\mathrm{m}}$ in this rainfall event decreased by $24.21 \%$, and the average value of $\log _{10} N_{\mathrm{w}}$ in this rainfall event increased by $14.69 \%$. Relatively lower 
values of $D_{\mathrm{m}}$ but higher values of $\log _{10} N_{\mathrm{W}}$ are observed compared with those data derived from the Yangjiang DSD data for convective precipitation. It indicates raindrops are smaller, but they have a higher number concentration in this rainfall event. The different DSD characteristics of this extremely heavy rainfall event provide a more challenging task when attempting to obtain accurate rainfall estimates.

Data pairs are divided into two classes according to the different hourly accumulations. The light-to-moderate rain $(<50 \mathrm{~mm})$ and heavy rain $(>50 \mathrm{~mm})$ are shown in Figure $9 \mathrm{~b}, \mathrm{c}$, respectively. The corresponding rain rate observed at AWSs is also shown in Figure 9e,f, respectively. As shown in Figure $9 \mathrm{~b}$, the light-to-moderate rain data can be easily divided into two parts according to the results. Most data in part 1 are underestimations, whereas most data in part 2 are overestimations. This is the reason that NB is close to 0 for the light-to-moderate rain (Table 5). The two parts listed above are observable in Figure 9c, whereas some data fall into part 3, where severe underestimations occurred. The algorithm underestimated the precipitation with small and midsize particles but overestimated the precipitation with midsize and large particles. When both $D_{\mathrm{m}}$ and $N_{\mathrm{w}}$ have large values, underestimations occurred. Severe underestimations for heavy rain are mainly due to these data categorized into part 3.

\subsection{Analysis of Factors Affecting QPE at the Three Stations}

Figure 10 shows the values of $R_{\mathrm{QPE}}$ (rain rate calculated with the QPE algorithm) minus $R_{\text {Gauge }}$ (rain rate measured at the AWS) at the three stations characterized by the heaviest rainfall. The colors represent the estimators used during this rainfall event; $R 1\left(K_{\mathrm{DP}}\right)$ was used for a certain period at station 2 , thus indicating that mixed precipitation existed during this period. Unfortunately, underestimations still occurred. $R\left(K_{\mathrm{DP}}, Z_{\mathrm{DR}}\right)$ is used most frequently, especially for stations 2 and 3 . However, $R\left(K_{\mathrm{DP}}\right.$, $\left.Z_{\mathrm{DR}}\right)$ underestimated the rain rate most often because it is not capable of adapting to large DSD variations that characterize severe rain; i.e., the principle reason for underestimations at each station.

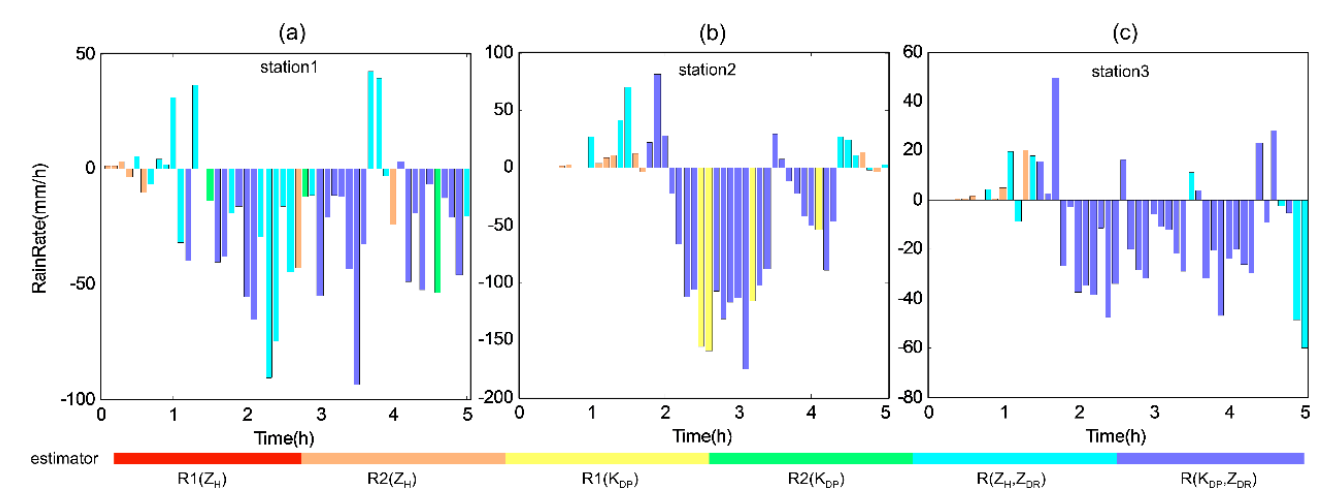

Figure 10. $R_{\mathrm{QPE}}$ (rain rate calculated with the QPE algorithm) minus $R_{\text {Gauge }}$ (rain rate measured at the AWS) at the three stations with the heaviest rainfall. (a-c) show the values for stations $1-3$, respectively. The different colors represent the various estimators used during this rainfall event.

Figure 11 shows time series of the vertical profiles of $Z_{\mathrm{H}}, Z_{\mathrm{DR}}, K_{\mathrm{DP}}, \rho_{\mathrm{HV}}$, and $\mathrm{Hcl}$ (Hydrometeor classification result) at the three stations where the heaviest rainfall occurred. Hcl is obtained according to the Hydrometeor classification algorithm described in $\mathrm{Wu}$ et al. [27]. This algorithm has been verified with the Zhuhai radar, the first operational PR in Guangdong, China. Following the approach of Mohr and Vaughan [41], radar observations (except Hcl) with $S N R>20 \mathrm{~dB}$ at the nine PPIs above the stations were linearly interpolated to obtain the profiles of the polarimetric variables. The vertical resolution was $0.5 \mathrm{~km}$, and the temporal resolution was $6 \mathrm{~min}$. The time shown on the horizontal axis is identical to Figure 6. The black lines in Figure 11 denote the heights of radar observations used for 
precipitation estimation, namely $1.23,1.17$, and $1.34 \mathrm{~km}$ at stations $1-3$, respectively. The different heights correspond to the different distances between the radar and the three stations.
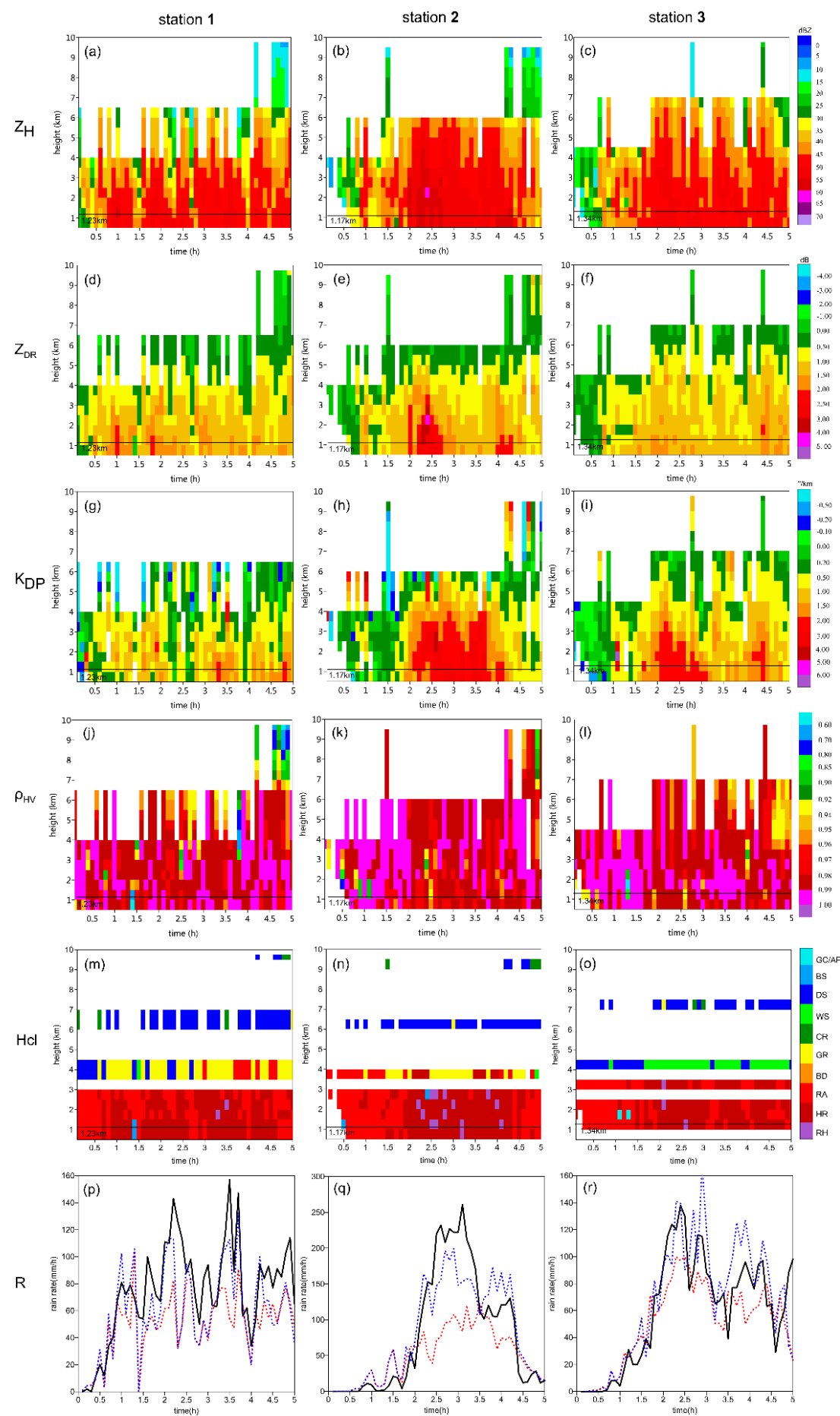

Figure 11. Time series of polarimetric radar $(\mathrm{PR})$ variables at the three stations where the heaviest rainfall occurred. The columns from left to right represent stations 1-3, and the rows from top to bottom show $Z_{\mathrm{H}}(\mathbf{a}-\mathbf{c}), Z_{\mathrm{DR}}(\mathbf{d}-\mathbf{f}), K_{\mathrm{DP}}(\mathbf{g}-\mathbf{i}), \rho_{\mathrm{HV}}(\mathbf{j}-\mathbf{1})$, and $\mathrm{Hcl}(\mathbf{m}-\mathbf{o})$. The panels $(\mathbf{p}-\mathbf{r})$ in the bottom (sixth) row show the time series of rain rate observed (solid lines) at each station and those derived from the radar data (red and blue dash lines: estimated by using algorithms presented in Sections 3.1 and 6, respectively). The black lines denote the observation heights used for precipitation estimation. 
The sounding data obtained near the precipitation area indicate that $0{ }^{\circ} \mathrm{C}$ was located around $5600 \mathrm{~m}$. However, the vertical profiles of the polarimetric variables show no significant signs of the melting layer, which is consistent with the characteristics of strongly convective precipitation. Figure 11 shows that the heavy precipitation at stations 1-3 was caused by four, two, and three convective cells, respectively.

At station 1, the four cells had similar $Z_{\mathrm{H}}$, but cells 1 and 2 had larger $Z_{\mathrm{DR}}$ and smaller $K_{\mathrm{DP}}$ compared with the other two cells, corresponding to a lower concentration of larger raindrops. The opposite is true for cells 3 and 4 . Rain rate derived from the radar data at $1.4 \mathrm{~h}$ is 0 , which is not correct. It is due to non-meteorological echoes at $1.4 \mathrm{~h}$ (Figure 11).

At station 2, the largest reflectivity ( $>60 \mathrm{dBZ}$ ) appeared at a height of $2.5 \mathrm{~km}$ during hours $2.4-2.5$ (Figure 11b), below which were large values of $Z_{\mathrm{DR}}$ and $K_{\mathrm{DP}}$ and small values of $\rho_{\mathrm{HV}}$, indicating an area of mixed graupel particles, hail particles, liquid water, and larger raindrops. In Figure $10, R 1\left(K_{\mathrm{DP}}\right)$ is used to estimate precipitation at hour 2.5, which means rain mixed with hail existed at this time. This is verified by $\mathrm{Hcl}$ in Figure 11n. Most of the mixed precipitation detection results from both algorithms are consistent. It indicates the result of the mixed precipitation detected by the algorithm presented in this study is credible. According to the results of the two algorithms, hail existed during hours 2-3. The underestimations of $R\left(K_{\mathrm{DP}}, \mathrm{Z}_{\mathrm{DR}}\right)$ at hours 2-3 (Figure 10) can probably be attributed to the abnormally large $Z_{\mathrm{DR}}$, which corresponds to larger raindrops produced by hail melting.

Compared with $K_{\mathrm{DP}}$ at station 1, that at station 3 was larger most of the time during this rainfall event, especially for hours 2-3.2 (Figure 11i). The strong echo at station 3 was caused mainly by the high concentration of raindrops, which also led to the large $K_{\mathrm{DP}}$. The larger $K_{\mathrm{DP}}$ mitigates the underestimations caused by $R\left(K_{\mathrm{DP}}, Z_{\mathrm{DR}}\right)$, which is used most of the time during this rainfall event (Figure 10c). This is the main reason why underestimation is not obvious at station 3.

Underestimations occurred at the three stations when hourly rainfall accumulation was quite large. PR data at station 1 during 2000-2400 UTC on 6 May 2017, data at station 2 during 2100-2300 UTC on 6 May 2017 and data at station 3 during 2200-2300 UTC on 6 May 2017 are used to calculate $D_{\mathrm{m}}$ and $N_{\mathrm{w}}$, which are shown in Figure 9d. Pink rectangles indicate data at station 1, and red rectangles indicate data at stations 2 and 3 . There are the mixtures of rain and hail at $1-1.5 \mathrm{~km}$ during these periods at stations 2 and 3 according to Hcl shown in Figure 11n,o. These red rectangles are found at the edge of the clusters that have relatively large $D_{\mathrm{m}}$ and $N_{\mathrm{w}}$. It is probably due to the melting hail. It indicates large concentrations of big rain drops in part 3 (Figure 9c) are probably associated with the melting hail. Considering that these particles in part 3 lead to severe underestimations, the melting hail is a reason for severe underestimations.

\section{The Improved Algorithm and Its Performance}

Analyses show that DSD characteristics in this rainfall event are significantly different from that of the average DSD in Yangjiang (estimators are derived from these DSD data), which is clearly evident at the three stations where the heaviest rainfall occurred. $R\left(K_{\mathrm{DP}}, Z_{\mathrm{DR}}\right)$ underestimates the rain rate most often at the three stations. It indicates $R\left(K_{\mathrm{DP}}, Z_{\mathrm{DR}}\right)$ is still sensitive to DSD variations when the extremely heavy rain occurs. In view of this problem, specific attenuation $A_{\mathrm{H}}$ is a good substitution variable for QPE. The low sensitivity of $R\left(A_{\mathrm{H}}\right)$ relation to DSD variability is well known and pointed out by Atlas and Ulbrich [20] and Matrosov [21]. A method that using $N_{\mathrm{W}}$ and $Z_{\mathrm{H}}$ to estimate $A_{\mathrm{H}}$ is used in this study [22]. The relationship between $\mathrm{x}=\log 10\left(Z_{\mathrm{H}} / N_{\mathrm{W}}\right)$ and $y=\log 10\left(A_{\mathrm{H}} / N_{\mathrm{W}}\right)$ can be expressed as

$$
y=a_{0}+a_{1} x+a_{2} x^{2}+a_{3} x^{3}
$$

where

$$
a_{0}=-6.12-0.012 t, a_{1}=0.622-0.0002 t, a_{2}=0.0250, a_{3}=0.00424,
$$

at S-band and $t$ is temperature $\left({ }^{\circ} \mathrm{C}\right)$. Equation (18) was obtained from long-term disdrometer data, as described by Ryzhkov [22]. Ryzhkov [22] considers $A_{\mathrm{H}}$ calculated from Equation (18) as the "true" 
value, and we use $Z_{\mathrm{H}}$ and $N_{\mathrm{W}}$ derived from the radar data to calculate $A_{\mathrm{H}}$ according to Equation (18). First, $R-A_{\mathrm{H}}$ relation is fitted by using $\mathrm{R}$ and $A_{\mathrm{H}}$ derived from Yangjiang DSD data with the least-squares method, which is expressed as

$$
R=2521 A_{\mathrm{H}}^{0.9302},
$$

where $R$ is in $\mathrm{mm} / \mathrm{h}$ and $A_{\mathrm{H}}$ is in $\mathrm{dB} \mathrm{km}^{-1}$. In the improved algorithm, $A_{\mathrm{H}}$ is derived from PR data and $R\left(A_{\mathrm{H}}\right)$ replaces $R\left(K_{\mathrm{DP}}, Z_{\mathrm{DR}}\right)$ to estimate heavy rainfall. Table 6 lists the evaluated statistical scores for the QPE estimated by algorithm before and after improvement. The improved algorithm performs better for total rain in term of $\mathrm{NB}$, which is close to 0 . For heavy rain, the performance of the improved algorithm is much better than the previous algorithm in terms of all the statistical indicators. After the improvement, RMSE and NE decreased by $40.29 \%$ and $37.70 \%$, respectively. In particular, Eff changes from -0.21 to 0.57 , indicating that, the QPE is worse and significantly better than the mean value of rain observed before and after improvement, respectively.

Table 6. Evaluated statistical scores for the QPE estimated by algorithm before and after improvement.

\begin{tabular}{cccccccc}
\hline $\begin{array}{c}\text { Algorithm } \\
\text { Improvement }\end{array}$ & $\begin{array}{c}\text { Hourly } \\
\text { Accumulation }\end{array}$ & CC & RMSE (mm) & NE (\%) & NB (\%) & Eff & NUM \\
\hline before & total & 0.88 & 7.48 & 37.61 & -7.20 & 0.77 & 1341 \\
before & $>50 \mathrm{~mm}$ & 0.68 & 28.84 & 30.40 & -29.43 & -0.21 & 40 \\
after & total & 0.89 & 7.44 & 37.85 & 0.29 & 0.77 & 1341 \\
after & $>50 \mathrm{~mm}$ & 0.83 & 17.22 & 18.94 & -9.62 & 0.57 & 40 \\
\hline
\end{tabular}

As shown in Figure 12, most high rain rate data are distributed in the red circle. The extremely heavy rain data observed at the three stations and the data in part 3 (Figure 9c) are also in the red circle. After algorithm improvement, $\mathrm{NE}$ corresponding to the heavy rain rate data decreased dramatically. Figure $12 \mathrm{~b}$ shows $\mathrm{NE}$ decreased percentage $\left(\left(\mathrm{NE}_{\text {before }}-\mathrm{NE}_{\text {after }}\right) / \mathrm{NE}_{\text {before }} \times 100 \%\right)$ after algorithm improvement of $\log _{10} N_{\mathrm{w}}$ versus $D_{\mathrm{m}}$. Most large value data are distributed in the red circle, which explains why NE decreased significantly when hourly accumulation was $>50 \mathrm{~mm}$. The same situation occurred for RMSE (not shown).

(a)

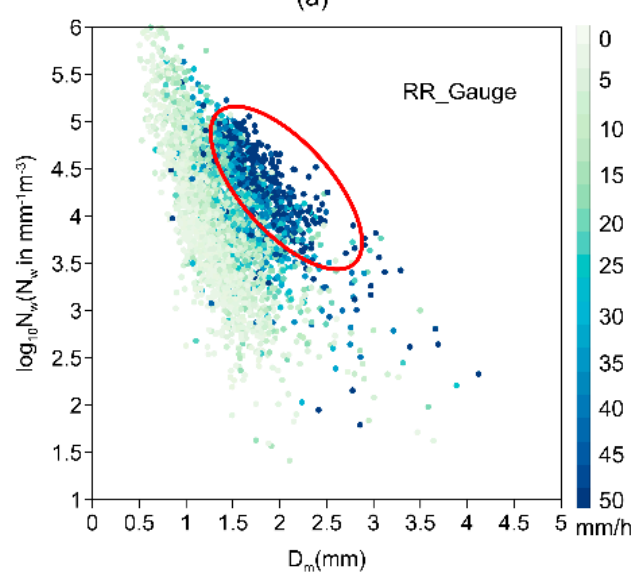

(b)

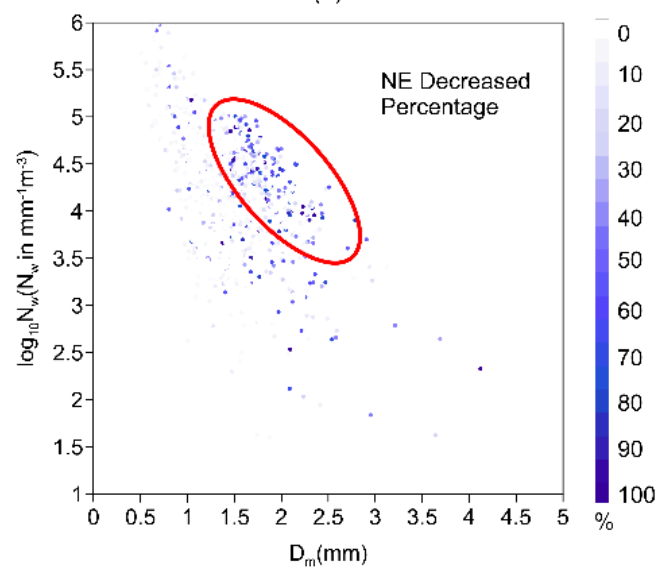

Figure 12. (a) Rain rate observed at the AWSs of $\log _{10} N_{\mathrm{w}}$ versus $D_{\mathrm{m}}$ derived from the PR data. Most high rain rate data are distributed in the red circle. (b) NE decreased percentage $\left(\left(\mathrm{NE}_{\text {before }}-\mathrm{NE}_{\mathrm{after}}\right) / \mathrm{NE}_{\text {before }} \times 100 \%\right)$ after algorithm improvement of $\log _{10} N_{\mathrm{W}}$ versus $D_{\mathrm{m}}$ derived from the PR data. Note that all these data are averaged from two adjacent data in time (average time: $12 \mathrm{~min})$.

Figure 13 shows the hourly radar or gauge rainfall accumulations at the three stations with the heaviest rainfall. The corresponding rain rate, which was estimated using the improved algorithm, 
is also shown in Figure 11p-r with blue dash lines. At the three stations, the performance of the improved algorithm also becomes better in terms of both rainfall accumulations and rain rate. Even though the improved algorithm overestimates rainfall during certain periods, most hourly rainfall accumulations are close to the AWS observations. At station 2, the new algorithm significantly improves compared with previous algorithm calculations during hours 3 and 4 when the DSD is affected by hail.

(a)

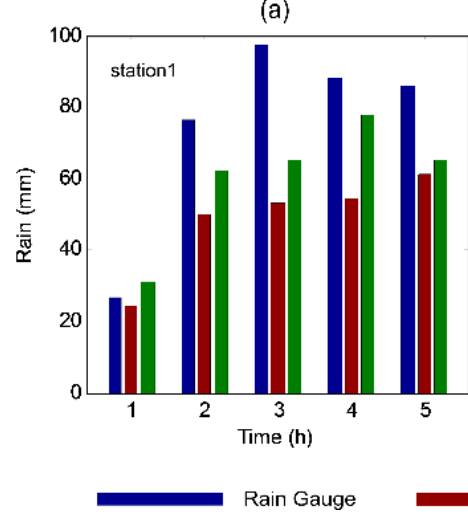

(b)

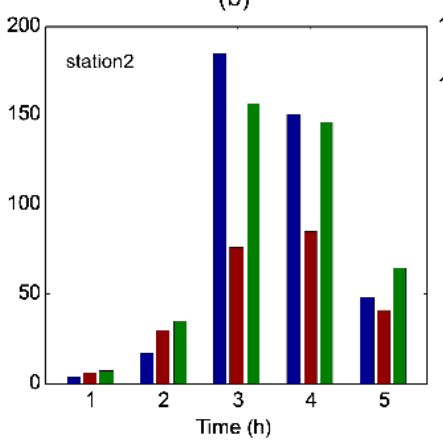

(c)

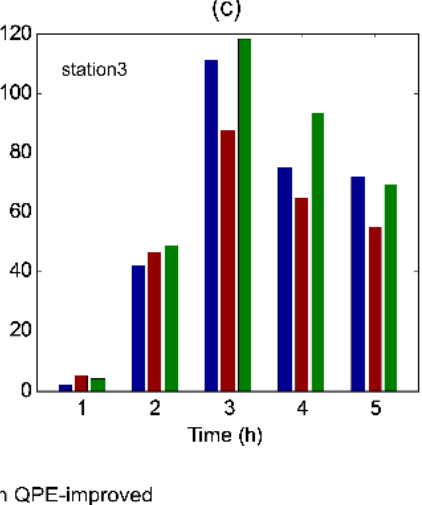

Figure 13. Hourly rainfall accumulations at stations where the largest rainfall accumulations were observed. $(\mathbf{a}-\mathbf{c})$ show the results of the algorithms at stations $1-3$, respectively. The column in blue indicates an AWS observation, the column in red indicates the radar estimate based on the unimproved algorithm, and the column in green indicates the radar estimate based on the improved algorithm.

After improvement, the algorithm performs much better than before because of the help of $R\left(A_{\mathrm{H}}\right)$. Rainfall estimation utilizing $A_{\mathrm{H}}$ has many advantages compared with algorithms based on $Z_{\mathrm{H}}$, $Z_{\mathrm{DR}}$, or $K_{\mathrm{DP}}$. It is least sensitive to DSD variations and immune to radar miscalibration, partial beam blockage, and the impacts of wet radomes [22]. Based on DSD-simulated data test, Thompson et al. [26] concluded that the $R\left(A_{\mathrm{H}}\right)$ estimator performed as well as the top-ranking $R\left(K_{\mathrm{DP}}, Z_{\mathrm{DR}}\right)$ estimator at S-band. However, despite recent attempts to improve $\Phi_{\mathrm{DP}}$ processing, reliable and robust routines for $K_{\mathrm{DP}}$ estimations do not exist at the moment [22]. The extremely heavy rain may make $K_{\mathrm{DP}}$ more unreliable than does moderate rain in this rainfall event; therefore, $R\left(A_{\mathrm{H}}\right)$ could be better than $R\left(K_{\mathrm{DP}}\right.$, $\left.Z_{D R}\right)$ when estimating the extremely heavy rain.

The improved algorithm performs well for heavy rain. How is the performance of this algorithm when it is used for light-to-moderate rainfall cases? The improved algorithm is used for the nine rainfall events listed in Table 2 to test its performance for light-to-moderate rainfall cases, and the evaluated statistical scores for these nine rainfall events are shown in Table 7.

Table 7. Evaluated statistical scores for light-to-moderate rain estimated using the improved algorithm.

\begin{tabular}{ccccccc}
\hline$\#$ & CC & RMSE (mm) & NE (\%) & NB (\%) & Eff & NUM \\
\hline 1 & 0.87 & 4.61 & 34.77 & 4.80 & 0.74 & 722 \\
2 & 0.86 & 4.86 & 39.19 & -7.33 & 0.74 & 2795 \\
3 & 0.87 & 4.14 & 38.76 & 3.49 & 0.75 & 1097 \\
4 & 0.86 & 3.62 & 43.08 & -24.67 & 0.71 & 6176 \\
5 & 0.88 & 3.78 & 41.89 & -6.72 & 0.76 & 3380 \\
6 & 0.86 & 2.92 & 40.83 & 11.55 & 0.70 & 3357 \\
7 & 0.85 & 3.05 & 43.56 & -1.52 & 0.69 & 498 \\
8 & 0.86 & 3.84 & 44.65 & 10.47 & 0.71 & 6212 \\
9 & 0.85 & 3.62 & 38.77 & 4.61 & 0.69 & 518 \\
\hline
\end{tabular}


For all nine rainfall events, NE ranges from $34.77 \%$ to $44.65 \%$, NB ranges from $-24.67 \%$ to $11.55 \%$, and Eff ranges from 0.69 to 0.75 . This improved algorithm presented for solving the heavy rain problem performed slightly worse than the original algorithm for the nine light-to-moderate rainfall cases. The performance for some rain cases becomes worse but for some becomes better. This is because the performance of $R\left(A_{\mathrm{H}}\right)$ is unstable when estimating light-to-moderate rain. $Z_{\mathrm{DR}}$ biases are larger for light rain than for heavy rain and the biases may propagate when $A_{\mathrm{H}}$ is estimated by using $N_{\mathrm{W}}\left(Z_{\mathrm{H}}\right.$, $Z_{\mathrm{DR}}$ ) (Equations (17) and (18)). The value of $A_{\mathrm{H}}$ at $\mathrm{S}$-band is very small for light-to-moderate rain and the small bias of $A_{\mathrm{H}}$ may bring a big bias of rain estimated by using $R\left(A_{\mathrm{H}}\right)$. These make the performance of $R\left(A_{\mathrm{H}}\right)$ unstable when estimating light-to-moderate rain. Considering that we have not yet figured out what kind of light-to-moderate rainfall is this new improved algorithm suitable for, this new algorithm is not suggested for light-moderate rain cases for now.

\section{Conclusions and Discussion}

In this study, we proposed a localized PR QPE algorithm that accounts for hydrometeor phase classification. The algorithm is used for nine different types of rainfall events as well as an extremely heavy rainfall event occurred in Guangzhou, China, on 6 May 2017, which is significantly different from conventional rainfall events, in which hourly rainfall accumulations are less than $50 \mathrm{~mm}$. Estimates were made for total rain, light-to-moderate rain (hourly accumulation $<50 \mathrm{~mm}$ ), and heavy rain $(>50 \mathrm{~mm})$. The estimates at three stations where total rainfall exceeded $300 \mathrm{~mm}$ were analyzed in particular during this rainfall event. To analyze the reasons for QPE error, a rain microphysics retrieval algorithm was presented to retrieve $D_{\mathrm{m}}$ and $N_{\mathrm{w}}$ from the PR measurements. The DSD characteristics of this extremely heavy rainfall event and the factors affecting QPE are analyzed based on $D_{\mathrm{m}}$ and $N_{\mathrm{w}}$. To improve the operational algorithm, $R\left(A_{\mathrm{H}}\right)$ replaces $R\left(K_{\mathrm{DP}}, Z_{\mathrm{DR}}\right)$ in the original algorithm to estimate heavy precipitation. The improved algorithm is also evaluated. The main conclusions are presented as follows.

(1) Persistent convergence and ascending motions occurred during this rainfall event, resulting in strong echoes that persisted for a long time. Radar echoes larger than $45 \mathrm{dBZ}$ lasted for a long time and moved slowly, leading to heavy rain over some areas of Guangdong. Compared with $Z_{\mathrm{DR}}$ derived from Yangjiang DSD data, $Z_{\mathrm{DR}}$ in this rainfall event are smaller for the same $Z_{\mathrm{H}}$, which is more obvious for the high occurrence frequencies data. The average values of $D_{\mathrm{m}}$ and $\log _{10} N_{\mathrm{w}}$ derived from the PR data in this rainfall event are $1.44 \mathrm{~mm}$ and 4.06, respectively. Compared with the values of data derived from the Yangiiang DSD data, the average value of $D_{\mathrm{m}}$ in this rainfall event decreased by $24.21 \%$ and the average value of $\log _{10} N_{\mathrm{W}}$ in this rainfall event increased by $14.69 \%$. In short, compared with the statistical DSD data in Yangjiang (estimators are derived from these data), this rainfall event was characterized by smaller average raindrop diameters and higher number concentration. These characteristics are more obvious in the heavy rainfall area.

(2) The bias ratio of MRMS for precipitation during the 2014 warm season is 1.06, which is slightly larger than that (1.00) of the algorithm presented in this study. NB and RMSE of the France operational radar system for intense rain (hourly accumulations $>5 \mathrm{~mm}$ ) in two rainfall events observed in 2010 are $-9 \%$ and $8.46 \mathrm{~mm}$, respectively. Compared with it, the algorithm presented in this study is slightly better in terms of similar NB $(-9 \%)$ and lower RMSE $(6.55 \mathrm{~mm})$ for the intense rain. The performance of the operational PR QPE algorithm presented in this study is satisfied when it estimates precipitation of all nine rainfall events. Even though precipitation estimates for light-to-moderate rain performed well, this algorithm severely underestimated heavy rain.

(3) The algorithm underestimated the precipitation with small and midsize particles but overestimated the precipitation with midsize and large particles. When $D_{\mathrm{m}}$ and $N_{\mathrm{w}}$ are both very large, underestimations occurred, and severe underestimations of heavy rain are mainly due to these particles. It is verified that some of these particles are associated with the melting hail. Even though most mixed precipitation was detected by the operational algorithm presented in this study, $R 1\left(K_{\mathrm{DP}}\right)$ underestimated mixed precipitation because it is not capable of adapting to large DSD variations for 
extremely heavy rain. $R\left(K_{\mathrm{DP}}, \mathrm{Z}_{\mathrm{DR}}\right)$ underestimates most heavy rain at the three stations because of the same reason.

(4) Even though $R\left(K_{\mathrm{DP}}, Z_{\mathrm{DR}}\right)$ is less susceptible to DSD variations than $R\left(Z_{\mathrm{H}}\right)$ [6], it still performs poorly for the extremely heavy rain in this rainfall event. In the improved algorithm, $R\left(A_{\mathrm{H}}\right)$ replaces $R\left(K_{\mathrm{DP}}, Z_{\mathrm{DR}}\right)$. After improvement, RMSE and NE decreased by $40.29 \%$ and $37.70 \%$, respectively, for the heavy rain in which hourly rainfall accumulations are more than $50 \mathrm{~mm}$. At station 2, the improved algorithm performed much better than the previous algorithm during hours 3 and 4 when DSD is affected by hail. These indicate that $R\left(A_{\mathrm{H}}\right)$ performs well for the extremely heavy rain.

There are still scarce PR observations of such extremely heavy rain events, and further studies of similar extremely heavy rain are necessary to verify the improved algorithm.

Author Contributions: Y.Z. (Yang Zhang) performed the experiments and data analysis. C.W. and Y.Z. (Yonghua Zhang) collected and analyzed some data. Y.Z. (Yang Zhang) and H.W. analyzed the results and prepared the manuscript. L.L. supervised the work and provided critical comments.

Funding: This work was jointly funded by the National Natural Science Foundation of China (41675023), Scientific Research Projects of CAMS (2017Z014), and the 2018 Open Research Program of the State Key Laboratory of Severe Weather (2018LASW-B08).

Acknowledgments: We would like to acknowledge the Guangdong Meteorological Observation Data Center for collecting and archiving the S-band polarimetric radar data, rain gauge data, and DSD data used in this study.

Conflicts of Interest: The authors declare no conflict of interest.

\section{References}

1. Bringi, V.N.; Chandrasekar, V. Polarimetric Doppler Weather Radar: Principles and Applications; Cambridge University Press: Cambridge, UK, 2001; ISBN 1139429469.

2. Gorgucci, E.; Chandrasekar, V.; Scarchilli, G. Radar and surface measurement of rainfall during cape: 26 July 1991 case study. J. Appl. Meteorol. 1995, 34, 1570-1577. [CrossRef]

3. Ryzhkov, A.V.; Zrnić, D.S. Comparison of dual-polarization radar estimators of rain. J. Atmos. Ocean. Technol. 1995, 12, 249-256. [CrossRef]

4. Ryzhkov, A.V.; Zrnić, D.S. Assessment of rainfall measurement that uses specific differential phase. J. Appl. Meteorol. 1996, 35, 2080-2090. [CrossRef]

5. Seliga, T.A.; Bringi, V.N.; Alkhatib, H.H. A preliminary study of comparative measurements of rainfall rate using the differential reflectivity radar technique and a raingage network. J. Appl. Meteorol. 1981, 20, 1362-1368. [CrossRef]

6. Ryzhkov, A.V.; Giangrande, S.E.; Schuur, T.J. Rainfall estimation with a polarimetric prototype of WSR-88D. J. Appl. Meteorol. 2005, 44, 502-515. [CrossRef]

7. Cifelli, R.; Chandrasekar, V.; Lim, S.; Kennedy, P.C.; Wang, Y.; Rutledge, S.A. A new dual-polarization radar rainfall algorithm: Application in Colorado precipitation events. J. Atmos. Ocean. Technol. 2011, 28, 352-364. [CrossRef]

8. Aydin, K.; Giridhar, V. C-band dual-polarization radar observables in rain. J. Atmos. Ocean. Technol. 2009, 9, 383-390. [CrossRef]

9. Wu, L. Application Study of Mobile C-band Dual-Polarization Radar Quality Control and QPE Using Raindrop Size Distribution. Ph.D. Thesis, Chinese Academy of Meteorological Sciences, Beijing, China, 2014.

10. Silvestro, F.; Rebora, N.; Ferraris, L. An algorithm for real-time rainfall rate estimation by using polarimetric radar: RIME. J. Hydrometeorol. 2009, 10, 227-240. [CrossRef]

11. Wu, Y.; Liu, L. Statistical characteristics of raindrop size distribution in the Tibetan Plateau and southern China. Adv. Atmos. Sci. 2017, 34, 727-736. [CrossRef]

12. Wu, Y.; Liu, L.; Zhou, Y.; Yang, J.; Zheng, J. Study of raindrop influence of spectrum change on precipitation estimation. Plat. Meteorol. 2016, 35, 220-230. (In Chinese) [CrossRef]

13. Zhang, Y.; Liu, L.; He, J.; Wen, H. Application of raindrop size distribution data from a disdrometer network to quantitative precipitation estimation. Torr. Rain Dis. 2016, 35, 173-181. (In Chinese) [CrossRef]

14. Libertino, A.; Allamano, P.; Claps, P.; Cremonini, R.; Laio, F. Radar estimation of intense rainfall rates through adaptive calibration of the Z-R relation. Atmosphere 2015, 6, 1559-1577. [CrossRef] 
15. Gou, Y.; Liu, L.; Yang, J.; Wu, C. Operational application and evaluation of the quantitative precipitation estimates algorithm based on the multi-radar mosaic. Act. Meteor. Sin. 2014, 72, 731-748. (In Chinese) [CrossRef]

16. Chandrasekar, V.; Bringi, V.N.; Balakrishnan, N.; Zrnić, D.S. Error structure of multiparameter radar and surface measurements of rainfall. part III: Specific differential phase. J. Atmos. Ocean. Technol. 1990, 7, 621-629. [CrossRef]

17. Giangrande, S.E.; Ryzhkov, A.V. Estimation of rainfall based on the results of polarimetric echo classification. J. Appl. Meteorol. Clim. 2008, 47, 2445-2462. [CrossRef]

18. Wang, J.; Liu, L.; Cao, J. A comparison of methods of rainfall rate measurements by dual linear polarization Doppler radar. Meteor. Mon. 2005, 31, 25-30. (In Chinese) [CrossRef]

19. Golestani, Y.; Chandrasekar, V.; Bringi, V.N. Intercomparison of multiparameter radar measurements. In Proceedings of the Program 24th Conference on Radar Meteorology, Boston, MA, USA, 27-31 March 1989; American Meteor Society: Boston, USA, 1989; pp. 309-314.

20. Atlas, D.; Ulbrich, C.W. Path- and area-integrated rainfall measurement by microwave attenuation in the 1-3 cm band. J. Appl. Meteorol. 1977, 16, 1322-1331. [CrossRef]

21. Matrosov, S. Attenuation-based estimates of rainfall rates aloft with vertically pointing Ka-band radars. J. Atmos. Ocean. Technol. 2005, 22, 43-54. [CrossRef]

22. Ryzhkov, A.; Diederich, M.; Zhang, P.; Simmer, C. Potential utilization of specific attenuation for rainfall estimation, mitigation of partial beam blockage, and radar networking. J. Atmos. Ocean. Technol. 2014, 31, 599-619. [CrossRef]

23. Mishra, K.V.; Krajewski, W.F.; Goska, R.; Ceynar, D.; Seo, B.C.; Kruger, A.; Niemeier, J.J.; Galvez, M.B.; Thurai, M.; Bringi, V.N.; et al. Deployment and performance analyses of high-resolution iowa XPOL radar system during the NASA IFloodS campaign. J. Hydrometeorol. 2016, 17, 455-479. [CrossRef]

24. Keenan, T.D.; Carey, L.D.; Zrnić, D.S.; May, P.T. Sensitivity of 5-cm wavelength polarimetric radar variables to raindrop axial ratio and drop size distribution. J. Appl. Meteorol. 2010, 40, 526-545. [CrossRef]

25. Thurai, M.; Kumar, V.M.; Bringi, V.N.; Witold, F.K. Initial Results of a New Composite-Weighted Algorithm for Dual-Polarized X-Band Rainfall Estimation. J. Hydrometeorol. 2017, 18, 1081-1100. [CrossRef]

26. Thompson, E.J.; Rutledge, S.A.; Dolan, B.; Thurai, M.; Chandrasekar, V. Dual-polarization radar rainfall estimation over tropical oceans. J. Appl. Meteorol. Clim. 2018, 57, 755-775. [CrossRef]

27. Wu, C.; Liu, L.; Wei, M.; Xi, B.; Yu, M. Statistics-based optimization of the polarimetric radar Hydrometeor Classification Algorithm and its application for a squall line in South China. Adv. Atmos. Sci. 2018, 35, $296-316$. [CrossRef]

28. Ryzhkov, A.V.; Schuur, T.J.; Burgess, D.W.; Heinselman, P.; Zrnić, D.S. The Joint Polarization Experiment: Polarimetric Rainfall Measurements and Hydrometeor Classification. Bull. Am. Meteorol. Soc. 2005, 86, 809-824. [CrossRef]

29. Chen, G.; Zhao, K.; Zhang, G.; Huang, H.; Liu, S.; Wen, L.; Yang, Z.L.; Yang, Z.W.; Xu, L.; Zhu, W. Improving polarimetric c-band radar rainfall estimation with two-dimensional video disdrometer observations in eastern China. J. Hydrometeorol. 2017, 18, 1375-1391. [CrossRef]

30. Anagnostou, M.N.; Kalogiros, J.; Marzano, F.S.; Anagnostou, E.N.; Montopoli, M.; Piccioti, E. Performance evaluation of a new dual-polarization microphysical algorithm based on long-term $\mathrm{x}$-band radar and disdrometer observations. J. Hydrometeorol. 2013, 14, 560-576. [CrossRef]

31. Willis, P.T. Functional fits to some observed drop size distributions and parameterization of rain. J. Atmos. Sci. 1984, 41, 1648-1661. [CrossRef]

32. Testud, J.; Oury, S.; Amayenc, P. The concept of "normalized" distribution to describe raindrop spectra: A tool for hydrometeor remote sensing. Phys. Chem. Earth. 2000, 25, 897-902. [CrossRef]

33. Smith, P.L. Raindrop size distributions: Exponential or gamma-does the difference matter? J. Appl. Meteorol. 2003, 42, 1031-1034. [CrossRef]

34. Bringi, V.N.; Huang, G.; Chandrasekar, V.; Gorgucci, E. A methodology for estimating the parameters of a gamma raindrop size distribution model from polarimetric radar data: Application to a squall-line event from the TRMM/Brazil campaign. J. Atmos. Ocean. Technol. 2002, 19, 633-645. [CrossRef]

35. Brandes, E.A.; Zhang, G.; Vivekanandan, J. Comparison of polarimetric radar drop size distribution retrieval algorithms. J. Atmos. Ocean. Technol. 2004, 21, 584-598. [CrossRef]

36. Cao, Q.; Zhang, G.; Brandes, E.; Schuur, T.; Ryzhkov, A.; Ikeda, K. Analysis of video disdrometer and polarimetric radar data to characterize rain microphysics in Oklahoma. J. Appl. Meteorol. Clim. 2008, 47, 2238-2255. [CrossRef] 
37. Cao, Q.; Zhang, G.; Schuur, T.; Ryzhkov, A. Characterization of Rain Microphysics based on Disdrometer and Polarimetric Radar Observations. In Proceedings of the 2006 IEEE International Symposium on Geoscience and Remote Sensing, Denver, CO, USA, 31 July-4 August 2006; pp. 523-528. [CrossRef]

38. Cocks, S.B.; Zhang, J.; Martinaitis, S.M.; Qi, Y.; Kaney, B.; Howard, K. MRMS QPE performance east of the rockies during the 2014 warm season. J. Hydrometeorol. 2017, 18, 761-775. [CrossRef]

39. Jordi, F.I.V.; Tabary, P. The new french operational polarimetric radar rainfall rate product. J. Appl. Meteorol. Clim. 2013, 52, 1817-1835.

40. Bringi, V.N.; Chandrasekar, V.; Hubbert, J.; Gorgucci, E.; Randeu, W.L.; Schoenhuber, M. Raindrop size distribution in different climatic regimes from disdrometer and dual-polarized radar analysis. J. Atmos. Sci. 2003, 60, 354-365. [CrossRef]

41. Mohr, C.G.; Vaughan, R.L. An economical procedure for cartesian interpolation and display of reflectivity factor data in three-dimensional space. J. Appl. Meteorol. 1979, 18, 661-670. [CrossRef]

2018 by the authors. Licensee MDPI, Basel, Switzerland. This article is an open access article distributed under the terms and conditions of the Creative Commons Attribution (CC BY) license (http:/ / creativecommons.org/licenses/by/4.0/). 